\title{
OPEN The novel Dbl homology/ BAR domain protein, MsgA, of Talaromyces marneffei regulates yeast morphogenesis during growth inside host cells
}

\begin{abstract}
Harshini Weerasinghe ${ }^{1,2}$, Hayley E. Bugeja ${ }^{1}$ \& Alex Andrianopoulos ${ }^{1 \bowtie}$
Microbial pathogens have evolved many strategies to evade recognition by the host immune system, including the use of phagocytic cells as a niche within which to proliferate. Dimorphic pathogenic fungi employ an induced morphogenetic transition, switching from multicellular hyphae to unicellular yeast that are more compatible with intracellular growth. A switch to mammalian host body temperature $\left(37^{\circ} \mathrm{C}\right)$ is a key trigger for the dimorphic switch. This study describes a novel gene, $m s g A$, from the dimorphic fungal pathogen Talaromyces marneffei that controls cell morphology in response to host cues rather than temperature. The $m s g A$ gene is upregulated during murine macrophage infection, and deletion results in aberrant yeast morphology solely during growth inside macrophages. MsgA contains a Dbl homology domain, and a Bin, Amphiphysin, $\underline{R} v s$ (BAR) domain instead of a Plekstrin homology domain typically associated with guanine nucleotide exchange factors (GEFs). The BAR domain is crucial in maintaining yeast morphology and cellular localisation during infection. The data suggests that MsgA does not act as a canonical GEF during macrophage infection and identifies a temperature independent pathway in T. marneffei that controls intracellular yeast morphogenesis.
\end{abstract}

Host defence against disease causing microbes involves actively identifying and eliminating invading pathogens. This begins with the innate immune system where host phagocytes engulf and destroy these microbes, followed by triggering of an adaptive immune response. The success of a pathogen depends on its ability to escape the host response and for some pathogens this involves residing within particular phagocytic cells of the host where they are then able grow and proliferate. An important factor facilitating this lifestyle is the capacity to adopt a growth form suitable for the spatial constraints of the intracellular environment of a host cell. For many fungal pathogens that utilise the intracellular environment of macrophages as a means of immune system avoidance, morphological plasticity is an important virulence attribute ${ }^{1-6}$. This is exemplified by the dimorphic fungi, which display saprophytic, multicellular, filamentous hyphal growth in the external environment and are able to adopt a unicellular yeast growth form during infection. Dysregulation of morphology, leading to the production of a growth form that disrupts the integrity of the phagocytic cells, exposes the pathogen to the entire immune system.

Talaromyces marneffei (formerly Penicillium marneffei) is an intracellular human pathogen that exhibits temperature dependent dimorphic growth. At $25^{\circ} \mathrm{C}$ it grows in a multinucleate septate hyphal form that can differentiate to produce uninucleate asexual spores (conidia) ${ }^{7,8}$. At $37^{\circ} \mathrm{C}$ in vitro it grows as uninucleate yeast that divides by fission. The transition from hyphal cell or dormant conidium to a yeast cells proceeds by arthroconidiation, a process of filament fragmentation, in which nuclear and cellular division are coupled, double septa are laid down with subsequent cell separation producing yeast cells ${ }^{8}$. The transition from yeast cell to hyphal cell occurs by polarised growth at the tips of the elongate yeast cells and a switch to cell division by septation without subsequent cell separation.

The conidia are the infectious propagules and infection is believed to be initiated through their inhalation ${ }^{9}$. Once within the human host, T. marneffei conidia are engulfed by host primary alveolar macrophages where they bypass the process of arthroconidiation and germinate directly into yeast cells, which are the pathogenic

${ }^{1}$ Genetics, Genomics and Systems Biology, School of BioSciences, University of Melbourne, Victoria 3010, Australia. ${ }^{2}$ Department of Biochemistry and Molecular Biology, Biomedicine Discovery Institute, Monash University, Clayton 3800, Australia. ${ }^{\circledR}$ email: alex.a@unimelb.edu.au 
form. While hyphae and yeast are the predominant morphologies for T. marneffei, particular growth conditions manifest distinct differences in cell shape and length for some cell types. For instance, in vitro grown T. marneffei yeast cells have an elongated, filament-like morphology, whilst in vivo produced yeast cells are short, ellipsoid and compact, a form more suited for growing within the confines of the macrophage. As an intracellular pathogen the ability of T. marneffei to tightly regulate the dimorphic switch and maintain yeast morphology in the host is crucial for pathogenicity. Therefore, temperature drives the dimorphic switch and host signals modify yeast cell morphogenesis.

In a number of animal and plant pathogenic fungal species, cell type specific morphogenesis is controlled by signalling pathways involving the small GTPase molecular switches and their accessory factors; guaninenucleotide exchange factors (GEFs) and GTPase-activating proteins (GAPs) (reviewed in ${ }^{10}$ ). These play crucial roles in processes associated with cell shape such as control of polarized growth and cytoskeletal organisation. Rho-type GEFs are responsible for activating their small GTPase targets and their activity has been shown to regulate cytokinesis, cell wall integrity, antifungal resistance, viability, tissue invasive growth, mycotoxin production and virulence ${ }^{11-14}$. The majority of these studies have focused on GEFs containing canonical structural domains-a catalytic $\underline{D} b$ homology domain $(\mathrm{DH})$ domain and an auxiliary plekstrin homology (PH) domain, excluding the contribution of GEFs with alternate domain structures (reviewed in ${ }^{15}$ ).

In T. marneffei, a number of small GTPases of the Ras superfamily and associated downstream effectors have been shown to influence morphogenesis of all cell types in specific and distinct patterns, during growth under both in vitro and ex vivo (intracellular macrophage) growth conditions, by affecting polarity establishment and the differentiation of distinct cell types ${ }^{16}$. For example, the Cdc42 orthologue in T. marneffei, encoded by cflA, is required for correct yeast and hyphal cell morphogenesis in vitro, as well as germination of conidia but does not affect the various cell types or differentiation of asexual development structures (conidiophores). Whereas the Rac orthologue, encoded by $c f l B$, is important for hyphal cell morphogenesis and asexual development but not yeast cell morphogenesis ${ }^{17,18}$. In addition, orthologues of the p 21 activated kinases (PAK) Ste20 and Cla4, encoded by $p a k A$ and $p a k B$ respectively, are important for conidial germination and yeast cell morphogenesis at $37^{\circ} \mathrm{C}^{19,20}$. In particular pakB exclusively affects the formation of yeast cells during intracellular growth, suggesting that the pathways controlling morphogenesis of T. marneffei in vitro and during intracellular growth in host cells have some unique components that respond to distinct cues.

In a T. marneffei expression profiling study examining genes expressed during growth inside macrophages, a gene was identified that was specifically upregulated inside murine macrophages and was predicted to encode a RhoGEF-like protein (Weerasinghe et al. 2018 in prep). This previously uncharacterised gene that was named $m s g A$ (macrophage specific GEF-like A) is the only RhoGEF-like encoding gene in T. marneffei to show this specific pattern of expression. While MsgA contains a DH domain, unlike canonical GEFs, a Bin- $\underline{A}$ mphiphysin-

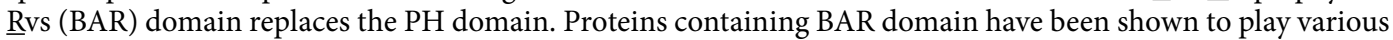
roles in membrane dynamics as well as interacting with small GTPases and many other proteins ${ }^{21-24}$. Deletion of $m s g A$ results in aberrant yeast morphology during macrophage infection but not during in vitro growth at $37^{\circ} \mathrm{C}$. Induced overexpression of $m s g A$ during in vitro growth resulted in yeast cell formation mimicking that of growth inside macrophages. Mutational analysis showed that the BAR domain of MsgA is crucial in establishing correct yeast morphogenesis and localisation during intracellular growth. Together these results define a novel host infection specific pathway that regulates intracellular morphogenesis in T. marneffei.

\section{Materials and methods}

Molecular methods and plasmid construction. T. marneffei genomic DNA was isolated as previously described $^{25}$. Southern and northern blotting was performed using Amersham Hybond $\mathrm{N}+$ membrane and $\left[\mathrm{a}^{-32} \mathrm{P}\right]$ dATP labelled probes by standard methods ${ }^{26}$. Sequences of primers are provided in Supplementary Table S1.

Deletion constructs were created using a modified Gateway ${ }^{\mathrm{Tw}}$ method $^{27}$. The deletion construct of $m s g A$ was created using pHW7711 containing the pDONR-pyrG cassette. Wildtype PCR product of msgA (PMAA_089500) was generated with primers VV55 and VV56 and cloned into pBluescript II SK+ to generate pHW7897. To make the deletion construct, pHW7905, PCR primers VV57 and VV58 were used to generate an inverse PCR product for the Gateway ${ }^{\text {ma }}$ reaction. To create a complementation construct, wildtype PCR product of $m s g A$ was cloned into the niaD targetting plasmid pHB7615 to generate pHW8053.

The overexpression allele $x y l P(p):: m s g A$ (pHW8056) was generated by PCR amplification of $2 \mathrm{~kb}$ of the $5^{\prime}$ promoter and ORF regions of the msgA gene using WW78 and WW77 to create subclone pHW8069. An inverse PCR product of pHW8069 was generated by amplification with primers WW79 and WW42 that excluded the promoter region. Subsequently the $x y l P(p)$ fragment PCR amplified from pHW8056 using H57 and H56 was phosphorylated and ligated to the inverse PCR fragment from pHW8069.

To generate the msgA::mCherry construct, pHW8053 was inverse PCR amplified using WW46 and WW57 and the resultant product was cut with XbaI. The $m$ Cherry fragment from pHW7911 was isolated by digestion with SpeI/EcoRV and this was ligated into the pHW8053 inverse PCR product to generate pHW7965.

To generate the $m s g A^{\Delta D H}$ and $m s g A^{\triangle B A R}$ domain deletion alleles, pHW8053 was inverse PCR amplified using WW59 and WW60 $(\triangle \mathrm{DH})$, and WW44 and WW45 $(\triangle \mathrm{BAR})$, and the resulting products were phosphorylated and self-ligated to produce pHW7966 and pHW7964 respectively. To generate the $m s g A^{\Delta D H}:: m C h e r r y$ and $m s g A^{\triangle B A R}:: m C h e r r y$ the same primers were used to inverse PCR from pHW7965 to generate pHW7962 and pHW7963.

Fungal strains and media. DNA-mediated transformation of T. marneffei was performed as previously

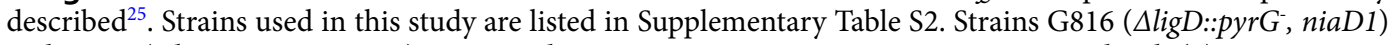
and G809 ( $\triangle$ ligD::pyrG $G^{+}$, niaD1) were used as recipient strains to generate $\triangle m s g A$ and $x y l P(p):: m s g A$ strains 
respectively ${ }^{28}$. The $\Delta m s g A$ strain was generated by transforming G816 with the XhoI/NotI fragment of pHW7905 to delete $m s g A$ from -200 to +6040 (relative to the translational start). Transformants were selected for uracil prototrophy. The $x y l P(p):: m s g A$ strain was generated by transforming G809 with the NruI/EcoRV fragment of pHW8056. Transformants were selected for glufosinate resistance. Strains bearing the $m s g A^{+}, m s g A:: m C h e r r y$, $m s g A^{\Delta \mathrm{BAR}}, m s g A^{\Delta \mathrm{DH}}, m s g A^{\Delta \mathrm{BAR}}:: m C h e r r y$ and $m s g A^{\Delta \mathrm{DH}}:: m$ Cherry alleles in a $\Delta m s g A$ background were generated by transforming G1003 with pHW8055, pHW7965, pHW7966, pHW7964, pHW7962 and pHW7963 respectively. These constructs were targeted to the niaD locus to generate strains G1045, G1046, G1047, G1048, G1049 and G1050 respectively. Homologous integration at niaD repairs the mutation in this strain, and transformants were selecting for their ability to utilise nitrate as a sole nitrogen source.

For induction of the $x y l P$ promoter during hyphal growth at $25^{\circ} \mathrm{C}$ in vitro, strains were grown in BHI medium with (inducing) or without (non inducing) $1 \%$ xylose for 4 days before microscopic observation. For growth in continuous inductive or non-inductive conditions, growth in each medium was extended for a further 2 days (total 6 days). For yeast growth at $37^{\circ} \mathrm{C}$ in vitro, strains were grown in $\mathrm{BHI}$ medium for 4 days then transferred to $\mathrm{BHI}$ medium with (inducing) or without (non inducing) $1 \%$ xylose for a further 2 days. For growth in continuous inductive or non-inductive conditions, strains were grown for 6 days in BHI with or without $1 \%$ xylose respectively.

In order to determine the septal span in hyphal cells for the wildtype and $x y l P(p):: m s g A$ during induced $m s g A$ expression, the distance between septa was measured for 100 subapical cellular compartments for both strains. Additionally to determine the branching frequency for the wildtype and $x y l P(p):: m s g A$ during induced $m s g A$ expression, the number of branch points along a $100 \mu \mathrm{m}$ section of subapical hyphal cells for ten hyphae was counted for both strains.

Preparation of RNA. RNA was isolated from two separate conditions for RT-PCR analysis. For the in vitro expression experiments RNA was isolated from FRR2161 (wildtype) yeast cells grown at $37^{\circ} \mathrm{C}$ for 6 days in liquid Brain Heart Infusion medium (BHI). For the macrophage infection expression experiments RNA was isolated from FRR2161 (wildtype) and $\triangle m s g A$ (G1003) cells isolated from infected lipopolysaccharide (LPS) (Sigma) activated J774 murine macrophages. J774 murine macrophages were seeded at a concentration of $1 \times 10^{6} / \mathrm{ml}$ into $175 \mathrm{~cm}^{3}$ sterile cell culture flasks in $20 \mathrm{~mL}$ of complete Dulbecco's Modified Eagle Medium (DMEM, 10\% foetal bovine serum, $8 \mathrm{mM} \mathrm{L}$-glutamine and $1 \%$ penicillin-streptomycin), incubated at $37^{\circ} \mathrm{C}$ for $24 \mathrm{~h}$ and then activated with $0.1 \mu \mathrm{g} / \mathrm{mL}$ LPS for $24 \mathrm{~h}$. Macrophages were washed in phosphate buffered saline (PBS) and $20 \mathrm{~mL}$ of complete DMEM containing $1 \times 10^{7}$ conidia was added. Macrophages were incubated for $2 \mathrm{~h}$ at $37^{\circ} \mathrm{C}$ (to allow conidia to be phagocytosed), washed once in PBS (to remove free conidia) and incubated a further $24 \mathrm{~h}$ at $37^{\circ} \mathrm{C}$. Macrophages were then treated with $4 \mathrm{ml}$ of $0.25 \% \mathrm{v} / \mathrm{v}$ Triton X solution for $2 \mathrm{~min}$ at room temperature to lyse the macrophages and extract T. marneffei. Both the lysate and T. marneffei grown in DMEM medium without macrophages were centrifuged at $2000 \mathrm{rpm}$ for $5 \mathrm{~min}$ at $4{ }^{\circ} \mathrm{C}$. The resultant pellets were washed in PBS and the RNA was extracted using TRIzol Reagent (Invitrogen) and a MP FastPrep-24 bead beater according to the manufacturer's instructions. RNA was DNase treated (Promega) prior to expression analysis.

Macrophage infection assay. J774 murine or THP-1 human macrophages were seeded at a concentration of $1 \times 10^{5} / \mathrm{ml}$ into a 6 well microtitre tray containing one sterile coverslip and $2 \mathrm{~mL}$ of complete DMEM (J774) or RPMI (THP-1) per well. J774 macrophages were incubated at $37^{\circ} \mathrm{C}$ for $24 \mathrm{~h}$ before activation with $0.1 \mu \mathrm{g} /$ mL LPS. THP-1 macrophages were differentiated with $32 \mu \mathrm{M}$ phorbol 12 -myristate 13 -acetate (PMA) at $37^{\circ} \mathrm{C}$ for $24 \mathrm{~h}$. Macrophages were incubated a further $24 \mathrm{~h}$ at $37^{\circ} \mathrm{C}$, washed in PBS and $2 \mathrm{~mL}$ of DMEM or RPMI medium containing $1 \times 10^{6}$ conidia was added. A control lacking conidia was also performed. Macrophages were incubated for $2 \mathrm{~h}$ at $37^{\circ} \mathrm{C}$ (to allow conidia to be engulfed), washed once in PBS (to remove free conidia) and incubated a further 24 or $48 \mathrm{~h}$ at $37^{\circ} \mathrm{C}$ after the addition of $2 \mathrm{~mL}$ of fresh DMEM or RPMI medium. Macrophages were fixed in $4 \%$ paraformaldehyde and stained with $1 \mathrm{mg} / \mathrm{mL}$ fluorescent brightener 28 (calcofluor, CAL) to observe fungal cell walls. Mounted coverslips were examined using differential interference contrast (DIC) and epifluorescence optics for cell wall staining and viewed on a Reichart Jung Polyvar II microscope. Images were captured using a SPOT CCD camera (Diagnostic Instruments Inc) and processed in Adobe Photoshop ${ }^{\mathrm{Tw}}$. The number of ungerminated conidia, germlings, filaments or yeast cells was recorded in a population of approximately 100 macrophages in three independent experiments. Filaments were defined as any fungal cell with at least one septum. Ellipsoid and elongated fungal cells with no septa were counted as yeast cells. Mean and standard error of the mean values were calculated.

Microscopic techniques for morphological analysis of T. marneffei. For morphological and general growth examination, T. marneffei was grown in liquid BHI (Oxoid) medium at $25^{\circ} \mathrm{C}$ for 2 days (hyphal growth) or $37^{\circ} \mathrm{C}$ for 4 days followed by transfer of approximately $10 \%$ of the culture to fresh medium for a further 2 days at $37^{\circ} \mathrm{C}$ (yeast growth). Aliquots of $500 \mu \mathrm{L}$ were transferred to $1.5 \mathrm{~mL}$ microfuge tubes containing $20 \mu \mathrm{L}$ of $4 \%$

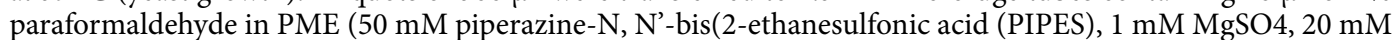
EGTA pH 6.7) fixing solution. Samples were incubated for $20 \mathrm{~min}$ at room temperature and then pelleted by centrifugation for $5 \mathrm{~min}$. The supernatant was removed and pellets were resuspended in $0.001 \% \mathrm{v} / \mathrm{v}$ Tween 80 supplemented with fluorescent brightener 28 (final concentration $0.014 \mathrm{mg} / \mathrm{mL}$ ) and observed microscopically.

Immunofluorescence microscopy. Immunofluorescence localization of the msgA::mCherry, $m s g A^{\Delta \mathrm{DH}}:: m$ Cherry and $m s g A^{\triangle \mathrm{BAR}}:: m$ Cherry strains was performed with anti-mCherry rat monoclonal primary antibody (Life Technologies) and an anti-rat ALEXA 488 conjugated goat secondary antibody (Molecular 
Figure 1. Relatedness of T. marneffei MsgA to other GEF-like proteins in fungi and expression of $m s g A$. (A) Bootstrapped relatedness tree of predicted Rho guanyl nucleotide exchange factor (GEF) proteins from a selection of dimorphic and monomorphic fungi. Black arrow indicates T. marneffei MsgA protein. The tree was generated using the maximum likelihood method based on JTT matrix model in CLUSTALW on MEGA7. Protein sequences are from Saccharomyces cerevisiae (Sc), Candida albicans (Ca), Aspergillus nidulans (AN), Aspergillus fumigatus (Afu), Histoplasma capsulatum (HCBG), Coccidioides immitis (CIMG), Paracoccidioides brasiliensis (PAAG), Talaromyces stipitatus (Ts) and Talaromyces marneffei (Tm). A previously characterised, archetypal member denotes each clade of Rho GEFs where possible: CDC24-like (CtlA), Bud3-like (BudC), RgfF, MsgA, TUS1-like (TusA) and ROM1/ROM2-like (RomB). MsgA belongs to a distinct class of Rho guanyl nucleotide exchange factor (GEF) proteins. (B) Expression of T. marneffei Rho GEF encoding genes across several growth conditions. These conditions include $24 \mathrm{~h}$ growth inside J774 murine macrophages (J774 macrophage infection) and THP-1 human macrophages (THP-1 macrophage infection), 24 h growth in macrophage-free cell culture media (J774 macrophage medium and THP-1 macrophage medium), 4 days hyphal growth at $25^{\circ} \mathrm{C}\left(25^{\circ} \mathrm{C}\right.$ in vitro $)$ and yeast growth at $37^{\circ} \mathrm{C}\left(37^{\circ} \mathrm{C}\right.$ in vitro $)$ in vitro. RNA was extracted and quantified by qRT-PCR analysis. MsgA shows upregulated expression during growth inside J774 macrophages. Error bars represent the standard error of the mean.

Probes) using standard protocols ${ }^{29}$. Immunofluorescence microscopy controls using only primary or secondary antibodies as well as an untagged strain were performed to confirm specificity of the antibodies.

Germination tests. For in vitro germination experiments, approximately $10^{5}$ spores were inoculated into $200 \mu \mathrm{L}$ of Synthetic Dextrose (SD) medium containing $10 \mathrm{mM}\left(\mathrm{NH}_{4}\right)_{2} \mathrm{SO}_{4}$ and incubated for 8,16 , or $24 \mathrm{~h}$ at $37^{\circ} \mathrm{C}$. The rates of germination were measured microscopically by counting the numbers of germinating conidia (conidia with a visible germ tube) in a population of approximately 100 fungal cells. Three independent experiments were performed. Mean and standard error of the mean values were calculated.

\section{Results}

The $m s g A$ gene encodes a unique RhoGEF-like protein with a distinctive domain structure and expression. The $m s g A$ gene was originally identified in an expression profiling study as showing specific transcriptional upregulation during intracellular growth of T. marneffei in J774 murine macrophages, relative to in vitro yeast or hyphal growth (Weerasinghe et al. 2018 in prep). Based on this expression profile and its domain structure the gene was denoted $m s g A$ (macrophage specific GEF-like). The $m s g A$ gene is one of six genes in the T. marneffei genome predicted to encode RhoGEF-like proteins. These are CtlA (Cdc24 orthologue), TusA (Tus1 orthologue), RomB (Rom1/Rom2 orthologue), BudC (Bud3 orthologue) and RgfF (RhoGEF 6), based on the annotations in Saccharomyces cerevisiae (Cdc24, Tus1 and Rom1/Rom2), Aspergillus nidulans (Bud3) or having been previously undesignated ( $m s g A$ and $r g f F$ ) (Fig. 1A). RhoGEF proteins from a number of dimorphic and/or pathogenic fungi were examined and while orthologues of MsgA exist in many phyla they are absent from the Saccharomycotina sub-phylum and Basidiomycete phylum. It is also clear that MsgA is part of a distinct clade of RhoGEF-like proteins.

Canonical RhoGEFs are composed of two distinct domains, a $\underline{D} b l$ homology domain (DH), which catalyses the exchange of GDP for GTP in Rho GTPases, and a Plekstrin homology domain (PH), which assists in localisation of GEFs and regulation of their activity $\left(\right.$ reviewed $\mathrm{in}^{15}$ ). Protein domain prediction analysis showed that $T$. marneffei RhoGEFs all contained a DH domain (Interpro ID: IPR000219) but showed differences in the composition of the second domain. CltA, TusA and RgfF have PH domains (Interpro ID: IPR001849), while RomA and BudC lack this domain. In contrast, MsgA has a $\underline{B} i n-\underline{A} m p h i p h y s i n-\underline{R} v s$ (BAR) homology domain (Interpro ID: IPR004148) downstream of the DH domain (Supplementary Fig. S1A), and no PH domain. BAR domains are known to interact with membranes to sense and promote membrane curvature as well as act as a binding platform for GTPases ${ }^{21,30}$. Additionally the predicted MsgA protein (1999 aa) is longer than other RhoGEFs, CtlA (932 aa), TusA (1781 aa), RomA (1217 aa), BudC (1546 aa) and RgfF (809 aa), and includes a large N-terminal region with no predicted domain motifs or localisation signals (Supplementary Fig. S1A). This N-terminal sequence contains a 26 glutamic acid repeat (Supplementary Fig. S1A). There is variation in the length of the acidic amino acid residue repeats in the MsgA orthologues from several clinical isolates of T. marneffei, ranging from 15 aa in isolates 3482 and 3841 to 26 aa in FRR 2161 (Supplementary Fig. S1B). This is despite the high degree of sequence conservation outside this region. Additionally this repeat is either greatly reduced or absent in closely related non-pathogenic, pathogenic and dimorphic species (Supplementary Fig. S1B and C). The significance of these dynamic strings of acidic amino acids is unclear at this stage but tandem repeated sequences (TRSs) have previously been shown to affect adhesion and host immune system evasion in other fungi ${ }^{31,32}$. A recent study of the genome structure of T. marneffei identified an increase in number of genes with TRSs compared to three other pathogenic and non-pathogenic filamentous fungi ${ }^{33}$.

To examine the expression of $m s g A$ in the context of the different morphological cell types exhibited by $T$. marneffei and with respect to its interaction with host immune cells, quantitative reverse transcriptase PCR (qRTPCR) was performed on RNA extracted from the wildtype T. marneffei grown in vitro at $25^{\circ} \mathrm{C}$, in vitro at $37^{\circ} \mathrm{C}$, intracellular growth in J774 murine and THP-1 human macrophages, as well as growth in macrophage-free cell culture media. The results show that $m s g A$ has $\sim$ ninefold higher expression during growth in J774 macrophages than in macrophage medium. The expression of $m s g A$ under the remaining growth conditions was consistently low, even when T. marneffei was growing inside THP-1 cells (Fig. 1B). Together these data suggest that $m s g A$ might have a unique role during intracellular growth in murine macrophages. 
A

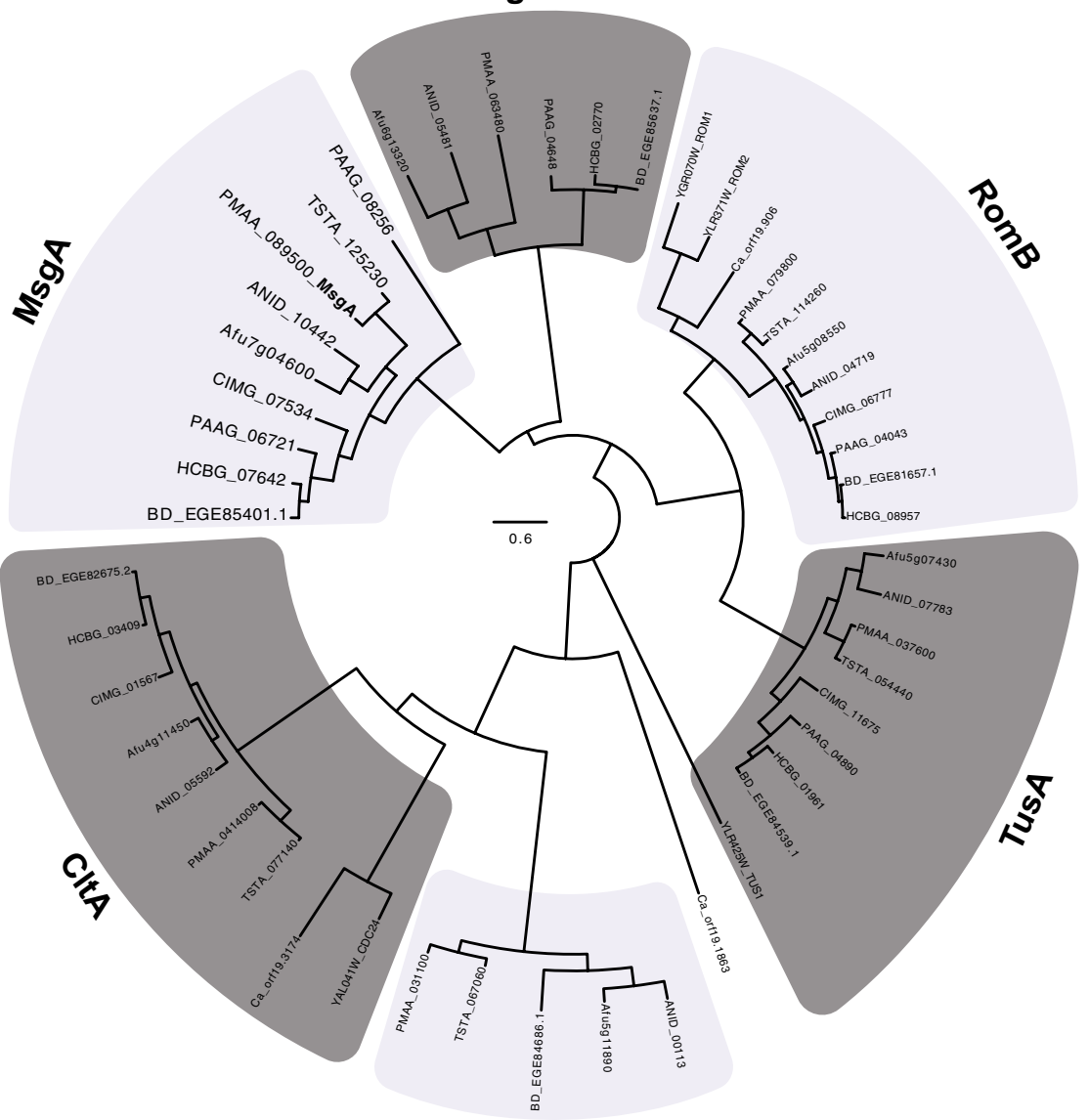

BudC

B

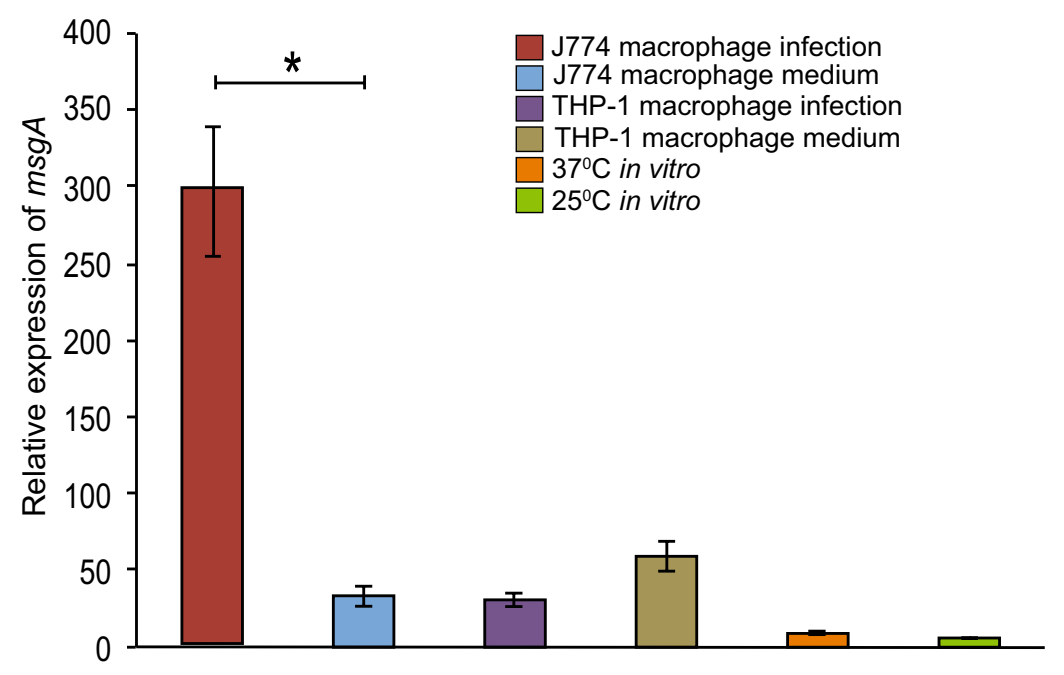


MsgA is required for the formation of yeast inside host cells. To characterise the role played by $m s g A$ during morphogenesis of T. marneffei, the gene was cloned, a deletion construct generated and this was used to create a deletion strain $(\triangle m s g A)$ by DNA-mediated transformation. To confirm that any resulting phenotypes were caused by this gene deletion, the $\triangle m s g A$ strain was complemented with the wildtype $\left(m s g A^{+}\right)$ allele targeted to the niaD locus. The wildtype $\left(m s g A^{+}\right), \triangle m s g A$ and $\triangle m s g A m s g A^{+}$strains were grown in liquid BHI medium at $25^{\circ} \mathrm{C}$ (hyphal) and $37^{\circ} \mathrm{C}$ (yeast) in vitro for 4 and 6 days respectively. At $25^{\circ} \mathrm{C}$ conidia from all three strains germinated normally and exhibited wildtype morphology, growing as polarized, branched septate hyphae. Similarly, at $37^{\circ} \mathrm{C}$ conidia from all three strains germinated and subsequently produced yeast cells (Fig. 2A). Thus the $\triangle m s g A$ and $\triangle m s g A m s g A^{+}$strains were indistinguishable from wildtype under in vitro growth conditions. This is consistent with the expression data in which the $m s g A$ transcript is present at very low levels during in vitro growth (Fig. 1B).

When these stains were used to infect LPS activated J774 macrophages the wildtype and $\triangle m s g A m s g A^{+}$strains were phagocytosed and germinated to produce small ellipsoid yeast cells that divided by fission after $24 \mathrm{~h}$. In contrast macrophages infected with $\triangle m s g A$ conidia were equally phagocytosed but contained more branched, septate filamentous-like cells after $24 \mathrm{~h}$ (Fig. 2B). Counts of the number of T. marneffei cells with at least one septum across approximately 100 infected macrophages showed that the wildtype and $\triangle m s g A m s g A^{+}$strains had $0.6 \pm 0.02 \%$ and $2.5 \pm 0.6 \%$ septate cells, respectively, while the $\Delta m s g A$ strain had $37.4 \pm 0.49 \%$ septate cells. Concomitantly, the $\triangle m s g A$ strain showed a reduction in the number of yeast cells during macrophage infection with $55.8 \pm 1.85 \%$ compared to $81.8 \pm 1.89 \%$ and $86 \pm 0.56 \%$ in the wildtype and $\triangle m s g A m s g A^{+}$strains respectively (Fig. 2C). Longitudinal cell length measurements showed that yeast cells produced by the $\triangle m s g A$ strain were on average 1.4 times longer than both the wildtype and the $\triangle m s g A m s g A^{+}$strains. This shows that $m s g A$ is important for correct yeast cell morphogenesis exclusively during macrophage infection.

Yeast cell morphogenesis in vitro occurs over days, rather than hours as seen inside host cells. A potential explanation for the aberrant yeast cell morphology inside macrophages could be that the cells are growing more slowly in the mutant. To test this hypothesis conidia of the wildtype, $\triangle m s g A$ and $\triangle m s g A m s g A^{+}$strains were used to infect J774 macrophages and examined after extended incubation for $48 \mathrm{~h}$ post infection. At this time point macrophages infected with all three strains contain a large number of yeast cells dividing by fission. Macrophages infected with the wildtype or $\triangle m s g A m s g A^{+}$strains showed similar yeast cell morphology that was short and oval shaped. In contrast, macrophages infected with the $\triangle m s g A$ strain contained long and cylindrical yeast cells with at least one septum compared to the long multi septate, filaments observed at $24 \mathrm{~h}$ post infection (Fig. 3A). The $\Delta m s g A$ strain yeast cells were 2.3 times longer than wildtype, being $8.9 \pm 0.57 \mu \mathrm{m}$, compared to wildtype and $\triangle m s g A m s g A^{+}$that were $3.9 \pm 0.12 \mu \mathrm{m}$ and $4.1 \pm 0.50 \mu \mathrm{m}$ respectively (Fig. 3B). As the $\Delta m s g A$ strain does not show germination defects either in vitro or during macrophage infection when compared to wildtype (Supplementary Table S3) and there are no morphological differences between the wildtype and $\triangle m s g A$ strains at 4,6 or $8 \mathrm{~h}$ postinfection ex vivo (data not shown), the elongated yeast cell morphology observed in the $\triangle m s g A$ strain during macrophage infection is unlikely to reflect a delay in germination. Rather it points to a requirement of $m s g A$ in maintaining the compact, ellipsoid yeast cell morphology specific to macrophage infection.

Aberrant morphogenesis of the $m s g A$ mutant is not due to defective host cell sensing. The germination and morphogenesis of dormant conidia, which are produced during the hyphal growth phase at $25^{\circ} \mathrm{C}$, into yeast cells differs in vitro compared to inside host cells. In vitro the conidia produce a polarised growth tip and generate multinucleate, multicellular hyphae before undergoing coupled nuclear and cell division to produce arthroconidiating hyphae. Fragmentation of these hyphae at septal junctions liberates uninucleate yeast cells ${ }^{7}$. Inside host cells conidia undergo isotropic growth upon germination and form yeast cells directly. The morphology of $\Delta m s g A$ mutant cells in J774 macrophages resembled arthroconidiating hyphae, so one explanation for the mutant phenotype is that they can no longer accurately sense the host environment. To test this the expression of four genes known to be expressed at $37^{\circ} \mathrm{C}$ in vitro, but with little to no expression during J774 macrophage infection was examined (Weerasinghe et al. 2018 in prep). RNA was extracted from the wildtype and $\triangle m s g A$ strains grown at $37^{\circ} \mathrm{C}$ in vitro or during J774 macrophage infection and used for RT-PCR analysis. While the four genes showed a clear transcript in the wildtype grown at $37^{\circ} \mathrm{C}$ in vitro, no expression was observed during the J774 macrophage infection condition for either wildtype or $\Delta m s g A$ (Supplementary Fig. S2). This suggests that the filaments and elongated yeast cells seen in the $\triangle m s g A$ strain are not similar to arthroconidial hyphae and yeast cells produced during wildtype growth in vitro at $37^{\circ} \mathrm{C}$, and $m s g A$ has a specific role in maintaining cell shape during macrophage infection.

MsgA also plays a role in the formation of yeast cells inside human cells. The expression level of msgA in human THP-1 macrophages is very low compared to murine J774 cells at the $24 \mathrm{~h}$ time point. To determine if the aberrant yeast cell morphogenesis phenotype of the $\triangle m s g A$ strain was limited to growth in J774 macrophages, THP- 1 cells were infected with conidia from wildtype, $\triangle m s g A$ and $\Delta m s g A m s g A^{+}$strains and observed at $24 \mathrm{~h}$ post infection (Supplementary Fig. S3A). The number of T. marneffei cells with at least one septum across approximately 100 infected macrophages showed that the $\triangle m s g A$ strain had a higher number of septate cells compared to either the wildtype and $\Delta m s g A m s g A^{+}$strains $(0.1 \pm 0.08 \%$ and $1.8 \pm 0.9 \%$ septate cells, respectively), while the $\Delta m s g A$ strain had $28.0 \pm 0.61 \%$. As expected, the $\triangle m s g A$ strain showed a reduction in the number of yeast cells during macrophage infection with $61.5 \pm 0.89 \%$ compared to $95.1 \pm 0.7 \%$ and $87 \pm 1.43 \%$ in the wildtype and $\triangle m s g A m s g A^{+}$strains respectively. The $\triangle m s g A$ yeast cells also displayed an increase in length $(8.6 \pm 0.25 \mu \mathrm{m})$ compared to wildtype $(4.9 \pm 0.09 \mu \mathrm{m})$ but were not as long, relative to wildtype, when growing inside J774 mouse cells (Supplementary Fig. S3B). This suggests that $m s g A$ also plays a role in yeast cell morphogenesis inside THP-1 macrophages, albeit less pronounced and without a marked increase in gene expression. 

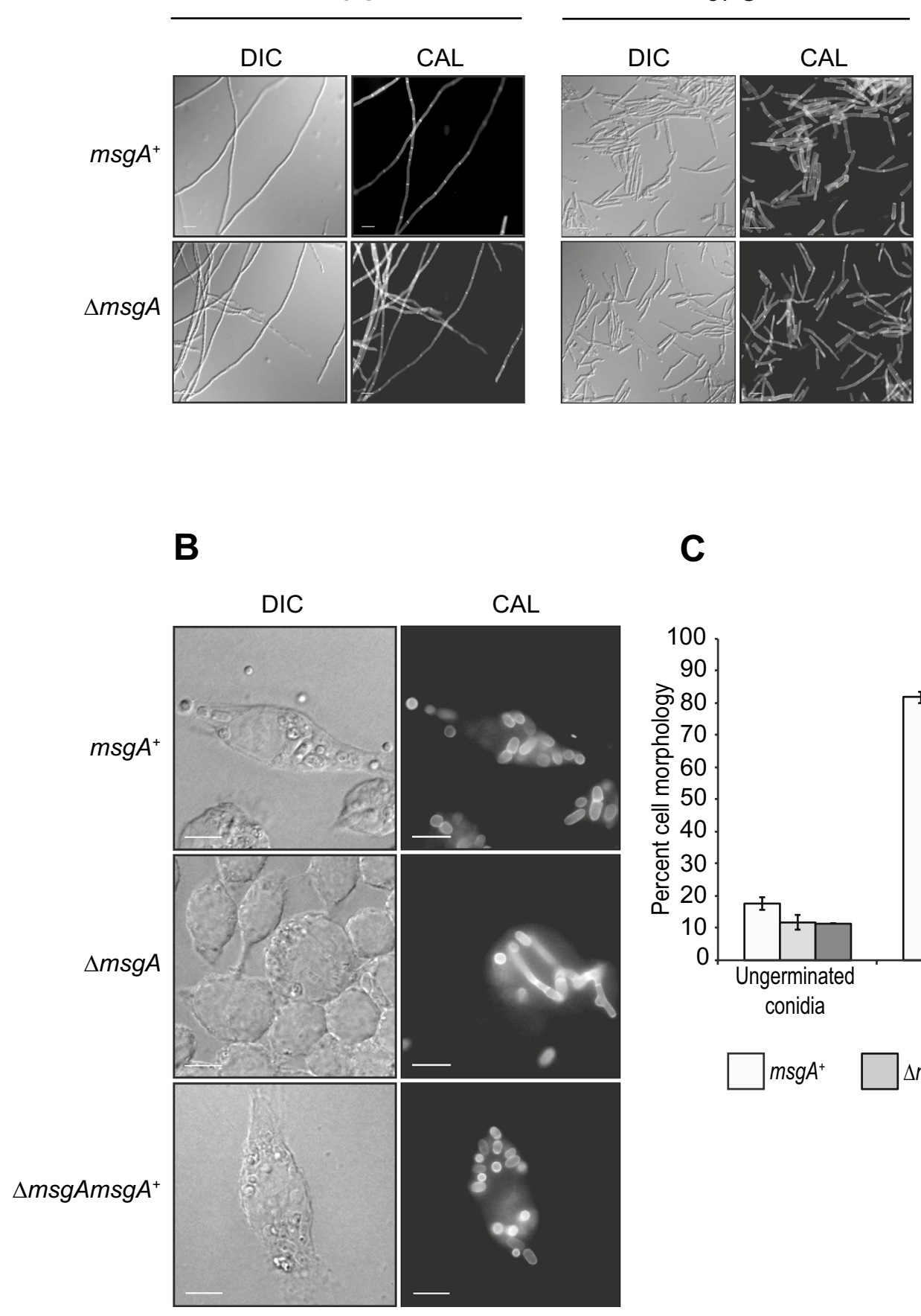

\section{C}

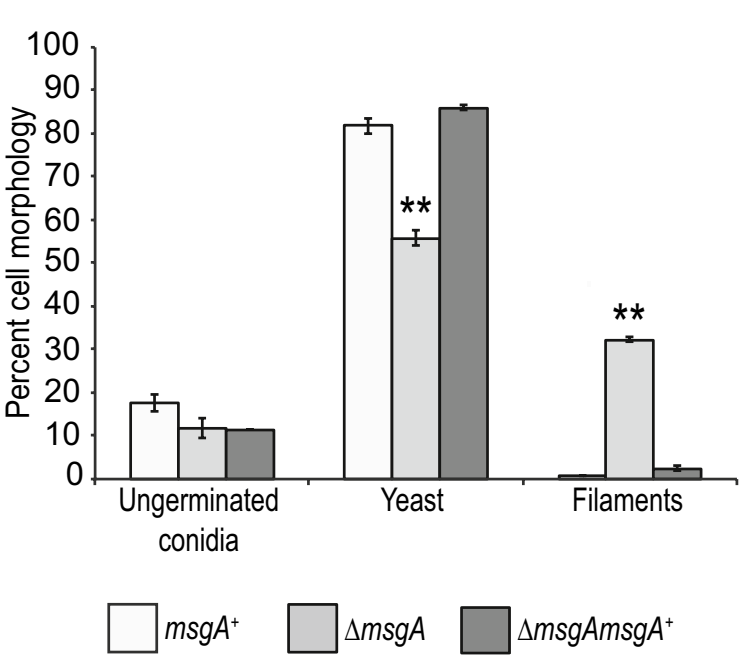

Figure 2. Deletion of $m s g A$ leads to aberrant growth inside macrophages. (A) The wildtype and $\triangle m s g A$ strains were grown on $\mathrm{BHI}$ medium at $25^{\circ} \mathrm{C}$ for 4 days and $37^{\circ} \mathrm{C}$ for 6 days, stained with calcofluor (CAL) and examined. Both strains show indistinguishable growth characteristics with respect to growth rate and morphology in the hyphal $\left(25^{\circ} \mathrm{C}\right)$ and yeast $\left(37^{\circ} \mathrm{C}\right)$ form. (B) LPS activated $\mathrm{J} 774$ murine macrophages were infected with conidia from the wildtype, $\Delta m s g A$ and complemented $\triangle m s g A m s g A^{+}$strains and examined microscopically. At $24 \mathrm{~h}$ post infection wildtype T. marneffei within J774 macrophages produced numerous ovoid yeast cells that divided by fission. In contrast the $\triangle m s g A$ mutant produced aberrantly shaped filaments, in addition to yeast cells. The complemented strain $\left(\Delta m s g A m s g A^{+}\right)$was indistinguishable from the wildtype. (C) The effects of deleting $m s g A$ on morphogenesis in macrophages were quantified at the $24 \mathrm{~h}$ post infection time point. The $\triangle m s g A$ mutant strain showed $37.4 \pm 0.49 \%$ septate filaments compared to the wildtype and complemented $\triangle m s g A m s g A^{+}$strains, which had $0.6 \pm 0.02 \%$ and $2.5 \pm 0.6 \%$ respectively. Additionally, the $\triangle m s g A$ strain showed a reduction in the number of yeast cells during macrophage infection with $55.8 \pm 1.85 \%$ compared to $81.8 \pm 1.89 \%$ and $86 \pm 0.56 \%$ in the wildtype and $\triangle m s g A m s g A^{+}$strains respectively. Error bars represent the standard error of the mean with $t$-test values falling in the following range ${ }^{\star *} \leq 0.05$. Images were captured using differential interference contrast (DIC) or with epifluorescence to observe calcofluor stained fungal cell walls (CAL). Scale bars are $10 \mu \mathrm{m}$. 
A

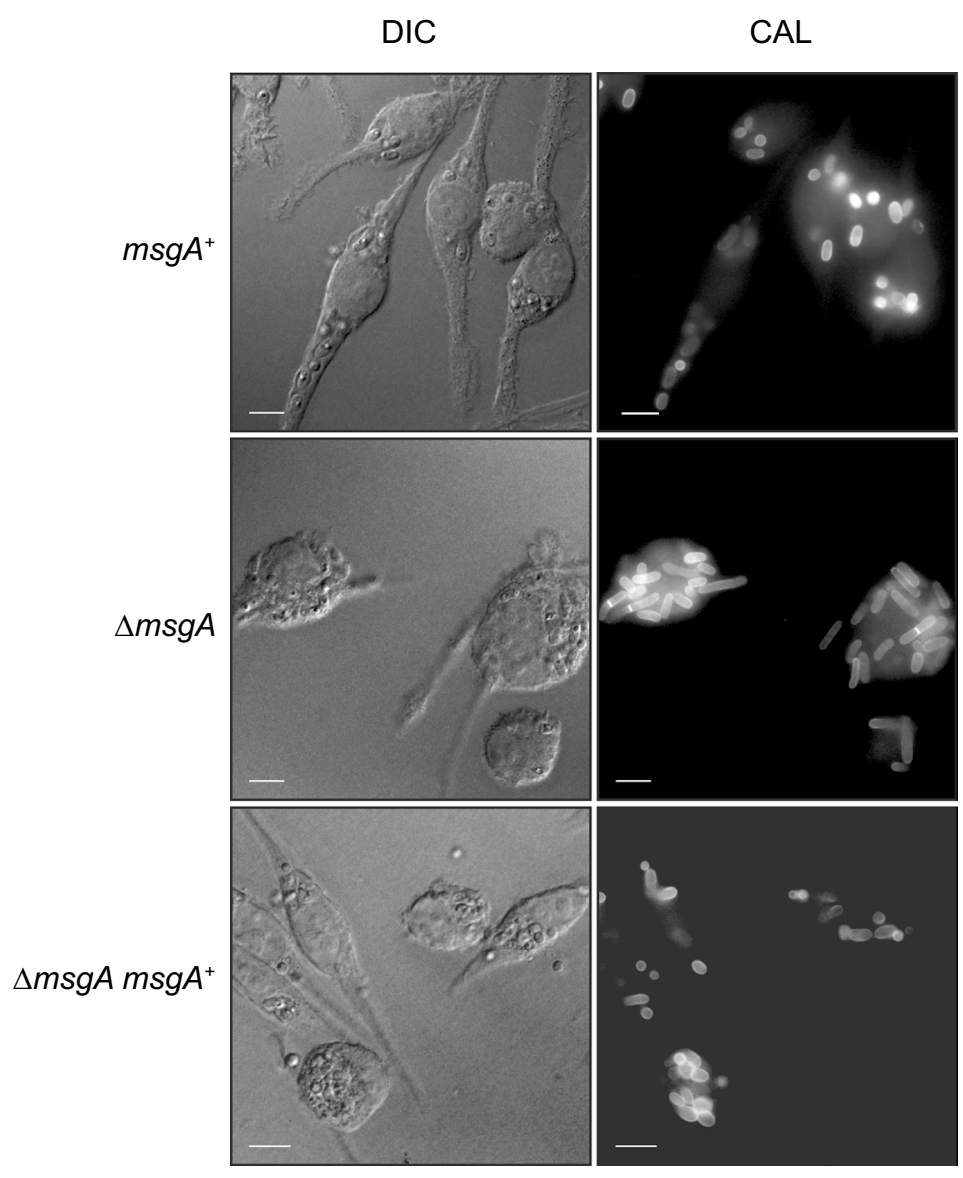

B

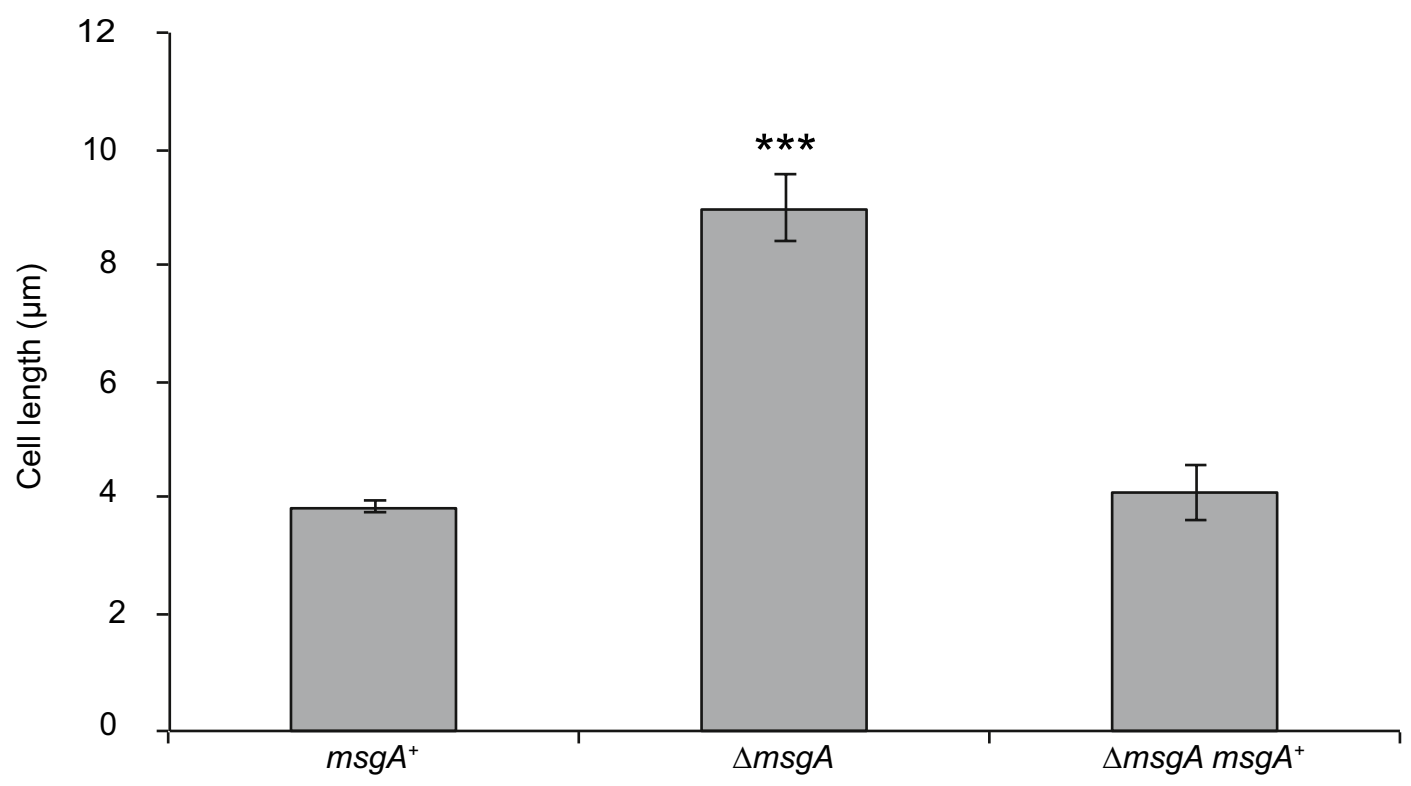


4Figure 3. Yeast cell formation defects in the $\Delta m s g A$ strain are not resolved with prolonged incubation in macrophages. LPS activated 7774 murine macrophages were infected with conidia from the wildtype, $\Delta m s g A$ and complemented $\triangle m s g A m s g A^{+}$strains and examined microscopically after prolonged incubation. (A) At $48 \mathrm{~h}$ post infection wildtype $\left(m s g A^{+}\right)$T. marneffei within $\mathrm{J774}$ macrophages retain their ovoid morphology producing numerous yeast cells that divided by fission. However the septate filaments produced by the $\triangle m s g A$ mutant strain at $24 \mathrm{~h}$ post infection continued to grow, producing long, cylindrical yeast cells, rather than breaking down to form short ellipsoid yeast cells (B) The effect of deleting $m s g A$ on morphogenesis in macrophages was quantified at the $48 \mathrm{~h}$ post infection time point. Wildtype yeast cells showed an average length of $3.9 \pm 0.12 \mu \mathrm{m}$ compared to the $\Delta m s g A$ mutant strain, which produced yeast cells of an average cells length of $8.9 \pm 0.57 \mu \mathrm{m}$, approximately 2.3 times longer than wildtype. The complemented strain $\left(\Delta m s g A m s g A^{+}\right)$produced yeast cells of $4.1 \pm 0.50 \mu \mathrm{m}$ in length and was comparable to wildtype. Error bars represent standard error of the mean with t-test values falling in the following range ${ }^{\star * \star} \leq 0.001$.

Overexpression of $m s g A$ produces aberrant hyphal morphology during growth at $25^{\circ} \mathrm{C}$. The $m s g A$ gene is important for yeast cell morphogenesis in macrophages and shows very little expression at $25^{\circ} \mathrm{C}$ and $37^{\circ} \mathrm{C}$ in vitro (Fig. 1A). In an attempt to gain more insight into the cellular activity of MsgA a construct that contained $m s g A$ under the control of a xylose inducible promoter, $x y l P$, was generated and used to transform T. marneffei strain G809 (Materials and methods). The wildtype and $x y l P(p):: m s g A$, strains were grown in BHI medium with (inducing) or without (non-inducing) 1\% xylose (Materials and Methods). On non-inducing medium the $x y l P(p):: m s g A$ strain was indistinguishable from wildtype at the microscopic levels. On inducing medium the $x y l P(p):: m s g A$ strain produced slightly swollen hyphae that displayed increased septation and hyper-branching along the hyphal length (Fig. $4 \mathrm{~A}$ ). The distance between adjacent septa was $38.6 \pm 0.9 \mu \mathrm{m}$ for the wildtype, $36.3 \pm 1.1 \mu \mathrm{m}$ for the $\Delta m s g A$ strain and $6.6 \pm 0.18 \mu \mathrm{m}$ for the $x y l P(p):: m s g A$ strain. The frequency of branching in sub-apical cells along hyphae was $1.15 \pm 0.11$ branches per $100 \mu \mathrm{m}$ of hyphal length for the wildtype, $1.06 \pm 0.51$ for the $\Delta m s g A$ strain and $11.05 \pm 0.81$ for the $x y l P(p):: m s g A$ strain. Branching in apical cells was not observed in any of the strains and there was no significant difference in the nuclear index between these strains (data not shown). Extended incubation up to 6 days under inducing conditions did not lead to the septate hyphae breaking down to form yeast cells. Therefore, the data shows that MsgA activity is required for specifying cell shape in host cells and can drive cell shape changes in vitro, possibly by affecting cell division.

Overexpression of $m s g A$ at $37^{\circ} \mathrm{C}$ in vitro mimics yeast cell morphogenesis during macrophage infection. Loss of $m s g A$ leads to the production of long and cylindrical yeast cells with in vitro morphology during macrophage infection rather than the wildtype short, ellipsoid cells. To test if MsgA could drive the development of yeast cell morphology at $37^{\circ} \mathrm{C}$ in vitro that mimics intracellular macrophage growth, yeast cells from the wildtype and $x y l P(p):: m s g A$ strains were transferred to BHI medium at $37^{\circ} \mathrm{C}$ both with (inducing) and without (non-inducing) $1 \%$ xylose (Materials and Methods). Under non-inducing conditions, the $x y l P(p):: m s g A$ strain was indistinguishable from wildtype, whereas on inducing medium the $x y l P(p):: m s g A$ strain produced yeast cells that were rounder and greatly reduced in length compared to wildtype (Fig. 4B), resembling those produced by T. marneffei during J774 macrophage infection (Fig. 4B). These yeast cells also displayed patchy, uneven chitin staining. Additionally the arthroconidial filaments that produce these yeast cells display aberrant chitin deposition and an increased septation frequency immediately adjacent to the fission division sites (similar to the induced $x y l P(p):: m s g A$ strain at $\left.25^{\circ} \mathrm{C}\right)$.

In vitro generated yeast cells consist of a mixture of arthroconidia (single cells formed by the separation of hyphal cells) and bona fide yeast cells (arthroconidial cells that have divided at least once). To determine if MsgA could drive the development of yeast cells directly from conidia at $37^{\circ} \mathrm{C}$ in vitro, as happens inside host cells, conidia from the wildtype, $\Delta m s g A$ and $x y l P(p):: m s g A$ strains were grown under continuous induction in BHI medium with $1 \%$ xylose. After 6 days the wildtype and $\triangle m s g A$ strains produce elongated yeast cells under both inducing and non-inducing conditions. In contrast, the $x y l P(p)::: m s g A$ strain produced small ellipsoid yeast cells similar to those observed when T. marneffei is growing inside host cells only under inducing conditions (data not shown). These observations were consistent with previous induction experiments. Additionally, under continuous induction the $x y l P(p):: m s g A$ strain produces a proportion of aberrantly shaped yeast cells, with uneven chitin deposition, that appear to produce yeast cells from multiple fission sites at the poles, often resulting in the production of two yeast cells from a singe pole (Fig. 4C). Sometimes these aberrant yeast cells, as well as long filamentous cells, produce cells that have lost their ellipsoid shape and seem to be dividing by budding rather than fission (Fig. 4D). Thus while the overexpression of $m s g A$ in vitro is able to recapitulate the phenotype of T. marneffei yeast cells grown within macrophages, continuous overexpression impedes yeast cell growth polarisation and results in inappropriate division.

MsgA is involved in conidial production during asexual development. During asexual development at $25^{\circ} \mathrm{C}$, wildtype T. marneffei colonies are composed of vegetative hyphae that produce asexual differentiated structures (conidiophores) from which green-pigmented asexual spores (conidia) are generated by basipetal budding ${ }^{25}$. The $\triangle m s g A$ mutant strain produced fewer conidia than wildtype, resulting in a paler colonial appearance (Supplementary Fig. S4A). Conidial counts of wildtype, $\triangle m s g A$ and $\triangle m s g A m s g A^{+}$strains revealed that the $\triangle m s g A$ strain produced $5.3 \times 10^{8} \pm 0.4$ conidia $/ \mathrm{ml}$ while the wildtype produced $23.9 \times 10^{8} \pm 0.9$ conidia/ $\mathrm{ml}$. The complemented $\Delta m s g A m s g A^{+}$strain did not completely rescue the phenotype of the $\Delta m s g A$ mutant strain with conidiation levels at $15.9 \times 10^{8} \pm 1.1$ conidia/ml (Supplementary Fig. S4B). The complementation allele included $891 \mathrm{bp}$ of promoter sequence, however examination of the 3624 bp region between the $m s g A$ 
Figure 4. Induced overexpression of $m s g A$ produces aberrant hyphae at $25^{\circ} \mathrm{C}$ and yeast cells with intracellular morphology at $37^{\circ} \mathrm{C}$ in vitro. The wildtype $\left(m s g A^{+}\right)$, inducible $(\triangle m s g A x y l P(p):: m s g A)$ and deletion mutant $(\triangle m s g A)$ allele strains were grown in liquid BHI medium supplemented with either $1 \%$ glucose (Uninduced) or $1 \%$ xylose (Induced) for 5 days at $25^{\circ} \mathrm{C}(\mathbf{A})$ or 6 days $37^{\circ} \mathrm{C}(\mathbf{B})$. Under uninduced conditions the $\Delta m s g A$ $x y l P(p):: m s g A$ strain is indistinguishable from $\triangle m s g A$ at both temperatures. (A) On inducing medium at $25^{\circ} \mathrm{C}$ the $\triangle m s g A x y l P(p):: m s g A$ strain shows increased septation (single arrowheads) and branching (double arrowheads) along the entire length of the hyphae but all other morphological and growth characters were indistinguishable amongst the strains. (B) On inducing medium at $37^{\circ} \mathrm{C}$ the $\triangle m s g A x y l P(p):: m s g A$ strain produced yeast cells that are rounder and greatly reduced in length compared to the $\triangle m s g A$ (single arrowheads). These yeast cells were dividing by fission and resembled yeast cells produced during growth inside macrophages. (C) Continuous induction over six days of growth of the $\Delta m \operatorname{sgA} x y l P(p):: m s g A$ strain produces yeast cells that have polarity defects at division (as represented by images of two distinct defective yeast cells from the culture population) and (D) a proportion of yeast cells appear to be dividing by budding (white triangle). Images were captured using differential interference contrast (DIC) or with epifluorescence to observe calcofluor stained fungal cell walls (CAL). Scale bars are $10 \mu \mathrm{m}$.

start codon and the upstream gene (PMAA_089490) identified four putative recognition sites for asexual development transcriptional regulators BrlA (5'-MRAGGGT-3', at - 1162 and - 3067) and AbaA (5'-CATTCY-3' at -339 and -1711$)$. Of these only one (AbaA at -339$)$ site was within the region included in the reintroduced allele. This may explain the partial complementation observed in the $\triangle m s g A m s g A^{+}$strain. A similar phenotype has been observed for the $d r k A$ gene in T. marneffei, which was attributed to the absence of BrlA and AbaA recognition sites ${ }^{34}$.

To test this hypothesis conidial density of the $m s g A$ over expression strain $(x y l P(p):: m s g A)$ was measured with and without induction. In the absence of induction the number of conidia produced the $x y l P(p):: m s g A$ strain was comparable to the $\triangle m s g A$ mutant strain, being $7.7 \times 10^{8} \pm 0.8$ conidia $/ \mathrm{ml}$. However in the presence of $0.5 \%$ xylose induction the conidiation level in the $x y l P(p):: m s g A$ strain was $35.2 \times 10^{8} \pm 1.5 \mathrm{conidia} / \mathrm{ml}$, which is comparable to wildtype $\left(33 \times 10^{8} \pm 1.5 \mathrm{conidia} / \mathrm{ml}\right)$ (Supplementary Fig. S4B). This supports the hypothesis that promoter elements excluded in the $m s g A^{+}$complementation allele are necessary for the proper expression of $m s g A$ during asexual development, and highlights a role for $m s g A$ during conidial production.

MsgA localisation suggests cell membrane association during macrophage growth. To investigate the localization of MsgA, the mCherry coding sequence was inserted into the C-terminal end of MsgA, after the DH domain. The $m s g A:: m$ Cherry fusion construct was targeted to the niaD locus in the $\Delta m s g A(\mathrm{G} 1003)$ strain. This strain was used to infect J774 murine macrophages and wildtype yeast cell morphology was evident after $24 \mathrm{~h}$ showing that the fusion allele complemented the $\Delta m s g A$ phenotype during macrophage infection (Fig. 5A). Immunostaining of these infected cells with an anti-mCherry antibody and calcofluor co-staining showed that MsgA-mCherry specifically localized to yeast cells but not to ungerminated conidia (Fig. 5B). Localization was observed around the cell periphery and in distinct punctate vesicular structures within the cytoplasm. Co-localization with calcofluor stained cell walls and septa was not observed, either at nascent septation sites prior to, or immediately after, cell wall deposition (Fig. 5B,C). However localization of MsgA was observed in the region immediately adjacent to the cell wall during cell separation (Fig. 5D,E). Brighter punctate structures of MsgA localization can be seen at the sites of cytokinesis in cells that are actively undergoing fission division. Thus MsgA is localised to, or closely associated with, cell membranes and vesicles during macrophage infection, with an increased presence at cell division sites late in the cell division process.

The BAR domain of MsgA is essential for proper yeast morphogenesis during macrophage infection. In order to examine the role of the conserved domains of MsgA in the phenotypes observed during macrophage infection, mutant alleles were generated that deleted the $\mathrm{DH}\left(m s g A^{\Delta \mathrm{DH}}\right)$ or $\mathrm{BAR}$ domains $\left(m s g A^{\triangle \mathrm{BAR}}\right)$. Domain deletion constructs were targeted to the niaD locus of the $\Delta m s g A(\mathrm{G} 1003)$ strain. These mutant strains were compared to the wildtype, the original deletion strain $(\triangle m s g A)$ and the wildtype complementation strain $\left(\triangle m s g A m s g A^{+}\right)$. Both the $m s g A^{\Delta \mathrm{DH}}$ and $m s g A^{\Delta \mathrm{BAR}}$ strains were indistinguishable from the control strains during in vitro growth at $25^{\circ} \mathrm{C}$ and $37^{\circ} \mathrm{C}$ (data not shown). When conidia from these strains were used to infect LPS activated J774 murine macrophages numerous yeast cells that were dividing by fission were present for the wildtype, $\triangle m s g A m s g A^{+}$and $m s g A^{\Delta \mathrm{DH}}$ strains after $24 \mathrm{~h}$. In contrast macrophages infected with $\triangle m s g A$ and $m s g A^{\triangle \mathrm{BAR}}$ strains contained both septate yeast as well as long septate filament cells (Fig. 6A). Macrophages infected with the $m s g A^{\triangle \mathrm{BAR}}$ strain contained $39.1 \pm 0.6 \%$ filaments of the total fungal load when compared to the $m s g A^{\Delta \mathrm{DH}}$ strain, which contained $0.8 \pm 0.4 \%$ filaments (Fig. $6 \mathrm{~B}$ ). Similar to the $\triangle m s g A$ strain, the $m s g A^{\triangle \mathrm{BAR}}$ strain exhibited fewer yeast cells compared to the $m s g A^{\Delta \mathrm{DH}}$ and wildtype strains (Fig. $6 \mathrm{~B}$ ). Here the $m s g A^{\triangle \mathrm{BAR}}$ strain produced $59.1 \pm 2.7 \%$ yeast cells compared to $84.4 \pm 0.5 \%$ in the $m s g A^{\Delta \mathrm{DH}}$ strain. Thus the $m s g A^{\triangle \mathrm{BAR}}$ allele did not complement the $\triangle m s g A$ mutation, indicating that the BAR domain is essential for normal yeast morphogenesis during macrophage infection. Both domain deletion alleles were also introduced into the wildtype strain but did not alter the wildtype phenotype under either the in vitro or intracellular macrophage growth conditions tested, suggesting that these alleles do not have a dominant interfering effect on the function of MsgA (data not shown).

To assess whether the DH or BAR deletion mutations affect the localization of MsgA during macrophage infection, mCherry tagged $m s g A^{\Delta \mathrm{DH}}$ and $m s g A^{\Delta \mathrm{BAR}}$ constructs were generated and targeted to the niaD locus in the $\triangle m s g A$ (G1003) strain. These strains were used to infect J774 murine macrophages and, as observed for the 

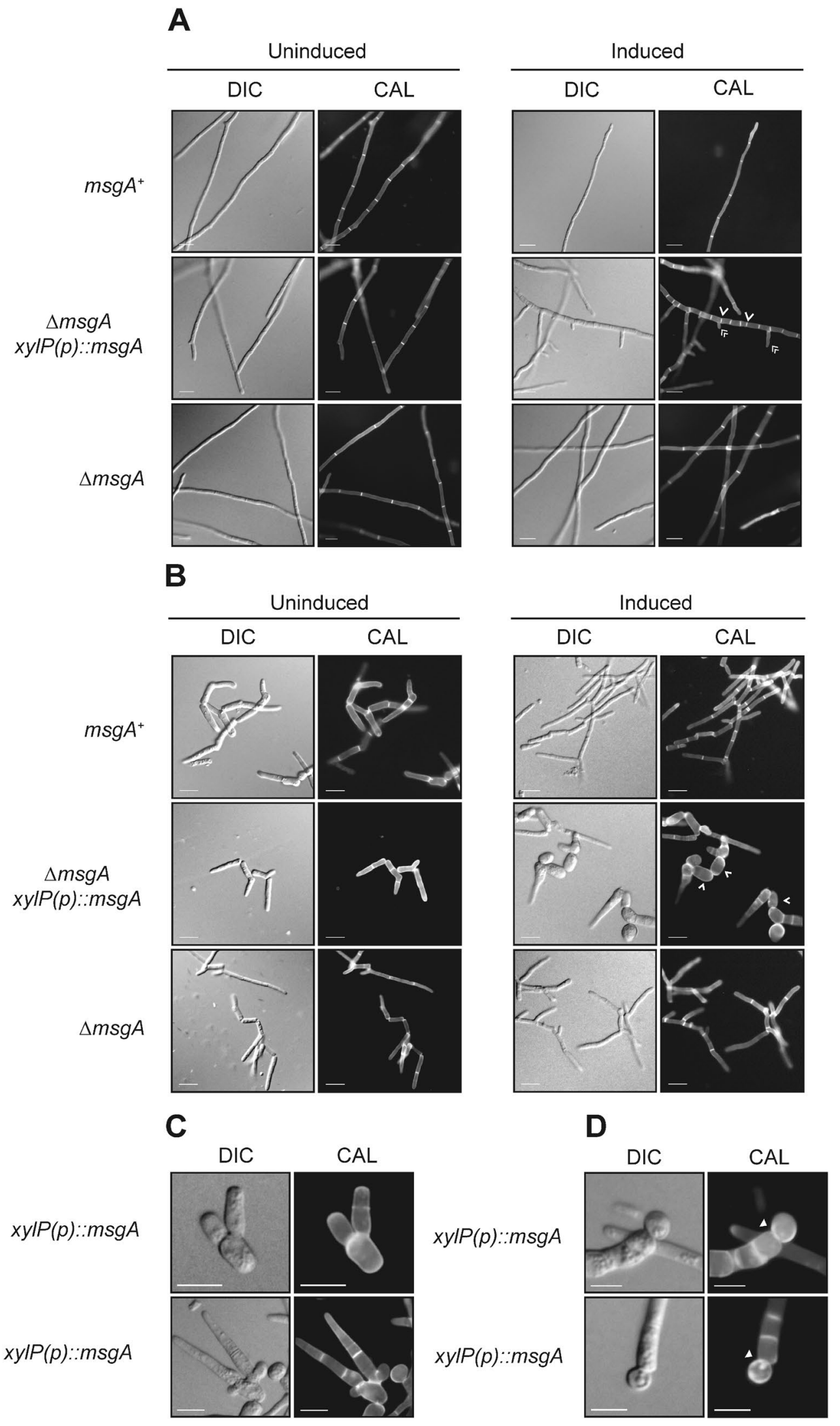
A
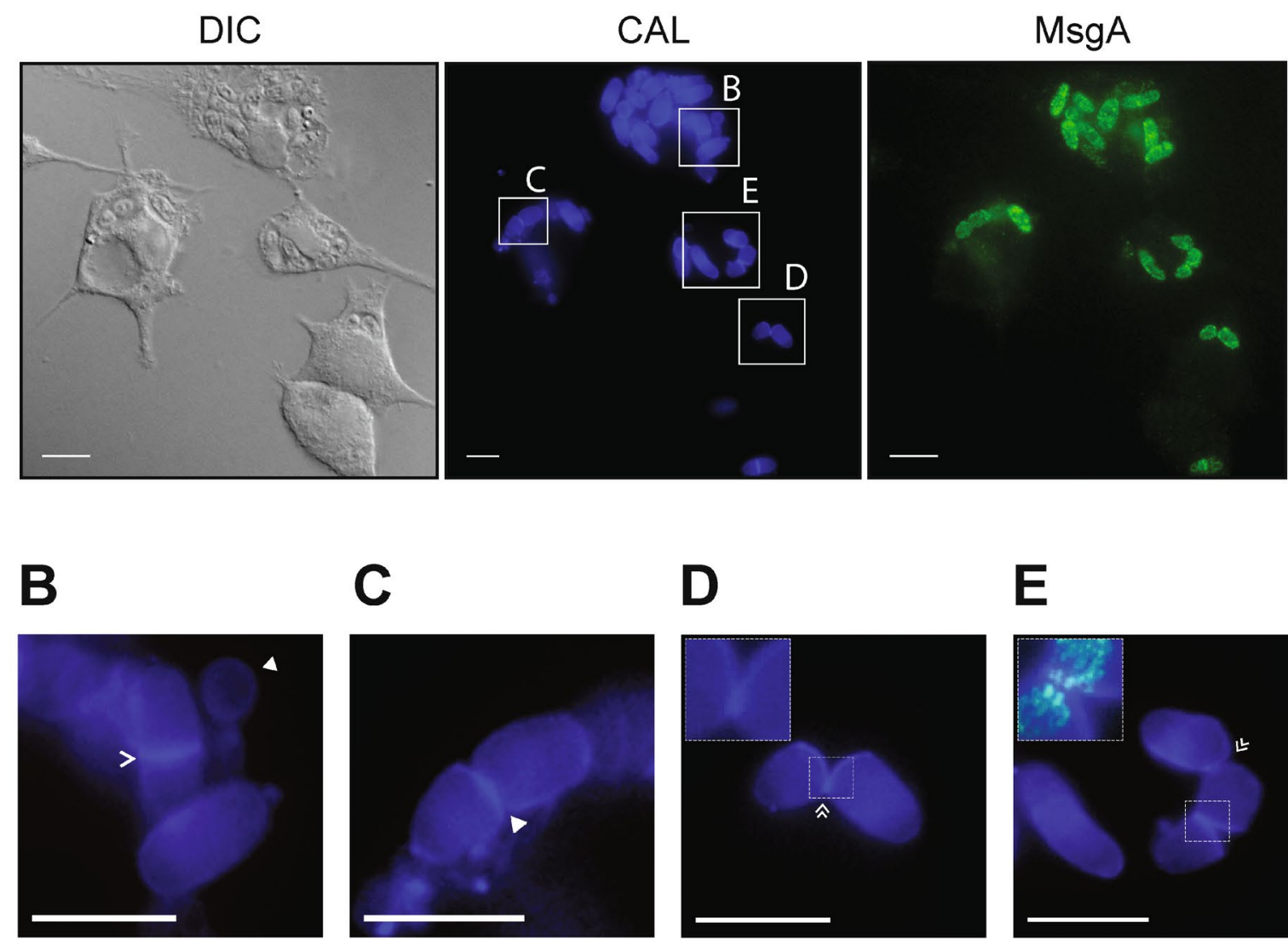
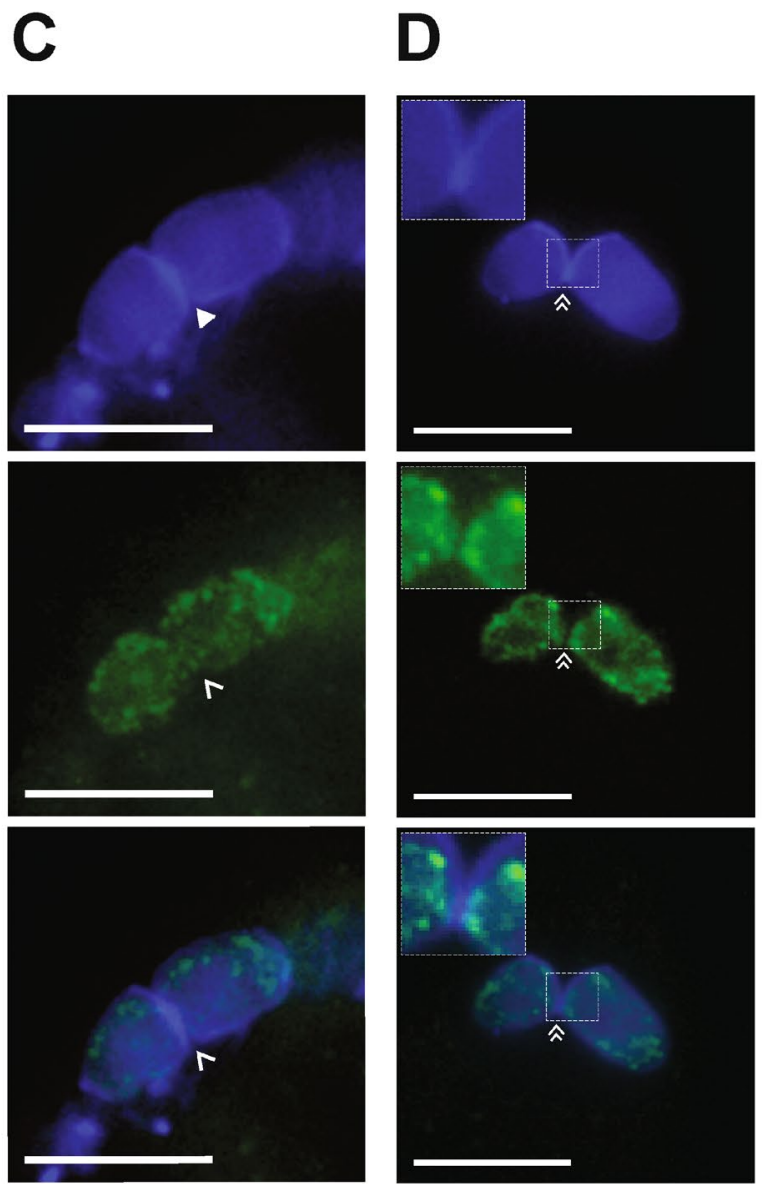
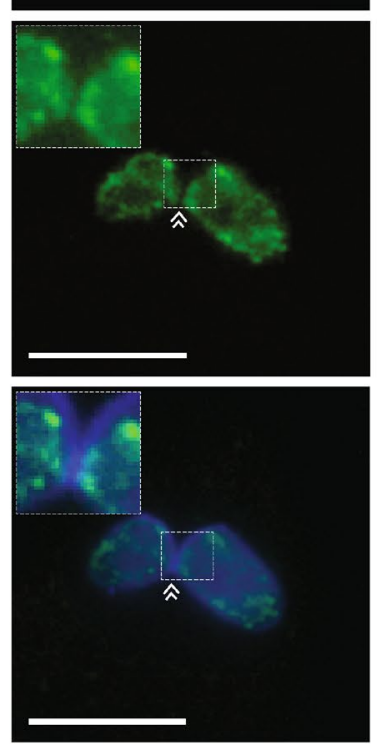
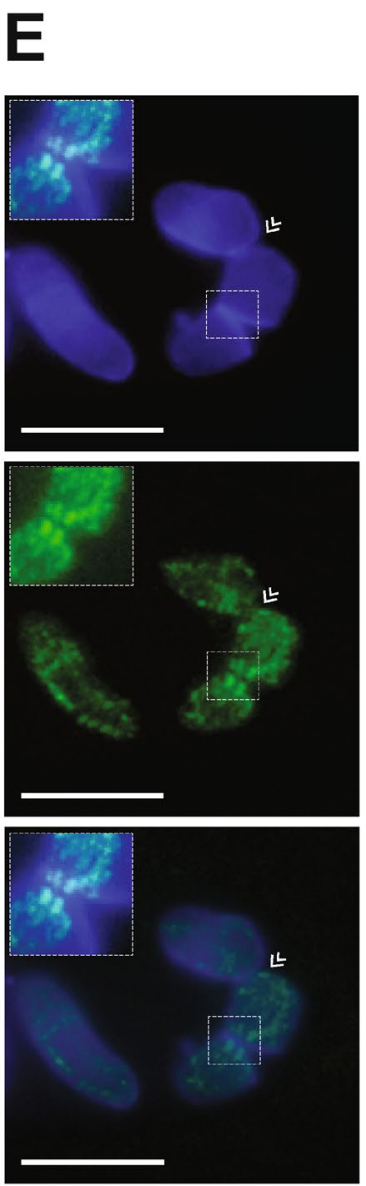

Figure 5. MsgA localisation during growth inside J774 murine macrophages. LPS activated J774 murine macrophages were infected with a strain expressing the $m s g A:: m$ Cherry fusion gene and incubated for $24 \mathrm{~h}$. Cells were fixed and the MsgA-mCherry fusion (MsgA) detected using an anti-mCherry rat monoclonal (3F10) primary and an anti-rat ALEXA488 goat secondary antibody. (A) Yeast cells were also stained with calcofluor (CAL) to highlight the fungal cell wall. The MsgA and CAL panels were also merged (Merge) to assess relative localisation. The inset boxes are expanded in panels (B-E) and further described below. (B) MsgA was only evident in actively growing yeast cells and not in ungerminated conidia (solid arrowhead). (D,E) In yeast cells MsgA is not localised to the cell wall but adjacent to it (zoomed in dashed line inset boxes), with punctate localisation at the cell periphery, as well as within the cytoplasm. (B) Localization is not evident either at nascent septation sites prior to, $(\mathbf{C})$ or immediately after (single arrowheads), cell wall deposition. (D,E) Instead it appears in a region immediately adjacent to septation sites during cell separation (double arrowheads). Images were captured using differential interference contrast (DIC) or with epifluorescence to observe calcofluor and ALEXA488 stained fungal features. Scale bars are $10 \mu \mathrm{m}$. 
non-mCherry fusion alleles, wildtype yeast cell morphology was evident after $24 \mathrm{~h}$ for the $m s g A^{\Delta \mathrm{DH}}:: \mathrm{mCherry}$ allele but not for the $m s g A^{\triangle B A R}:: m C h e r r y$ allele (Fig. 7). Immunostaining of these infected cells with an antimCherry antibody and calcofluor co-staining showed that the localisation pattern for the $\mathrm{MsgA}^{\Delta \mathrm{DH}}-\mathrm{mCherry}$ was the same as that of the MsgA-mCherry with punctate localisation in the cytoplasm and at the cell periphery and none at the cell wall either during cell wall deposition at the septa or during cytokinesis. In contrast, the

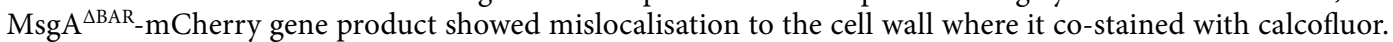
The MsgA ${ }^{\triangle B A R}$-mCherry gene product did not show the punctate pattern of localisation within the cytoplasm like wildtype and was not localized to nascent septation sites prior to or immediately after cell wall deposition (Fig. 7). However MsgA $\mathrm{ABAR}_{-}$mCherry showed weak localisation at the cell wall of septation sites during cell separation (Fig. 7). This suggests the possible late recruitment of MsgA to the cell separation complex.

\section{Discussion}

Survival and proliferation of microbial pathogens in a host relies on their ability to cope with host defence mechanisms and acquire nutrients for growth. For a number of prokaryotic and eukaryotic microbial pathogens this is coupled with the ability to grow inside cells of the host. In intracellular dimorphic pathogenic fungi, the ability to switch from a multicellular hyphal growth form into a unicellular yeast form that is more spatially suited to residing within host cells, is crucial for pathogenicity ${ }^{1,3,4}$. An important inducer of this switch is a shift to $37^{\circ} \mathrm{C}$ (mammalian body temperature), and this coincides with the conversion of infectious propagules to a pathogenic form. This study examined a previously uncharacterised $D b l$ homology/BAR domain protein encoded by $m s g A$, which is strongly upregulated in the dimorphic, human-pathogenic fungus T. marneffei during J774 murine macrophage infection and is critical for yeast morphogenesis in macrophages. It was demonstrated that $m s g A$ does not play a role in vitro, during yeast or hyphal cell morphogenesis at either $37^{\circ} \mathrm{C}$ or $25^{\circ} \mathrm{C}$, but does affect asexual development. Factors that are important for both yeast cell morphogenesis and asexual development have been identified previously. In particular studies of the cell signalling pathways in T. marneffei have uncovered similar effects for PakB, the CLA4 homologue encoding a p21-activated kinase, in yeast cell formation particularly during macrophage growth ${ }^{19}$. This reinforces the hypothesis that there are shared molecular mechanisms underlying asexual development and dimorphic switching programs. The data also indicates that morphogenesis in T. marneffei during infection may respond to a host internalisation triggered mechanism which induces the expression of $m s g A$ and other associated genes, and that the activation of this pathway drives cellular processes that responds to the host environment.

MsgA is involved in intracellular morphogenesis. The $m s g A$ gene has a unique expression profile that foreshadows its contribution to yeast cell morphogenesis during macrophage infection. In comparison to the other six Rho GEF encoding genes, msgA shows high level and specific expression in T. marneffei during J774 murine macrophage infection. Consistent with this expression pattern the $m s g A$ deletion strain displayed septate and branched filament production during intracellular growth but wildtype yeast cell morphogenesis in vitro at $37^{\circ} \mathrm{C}$. These aberrant ex vivo generated filaments were morphologically more similar to arthroconidia/yeast cells produced at $37^{\circ} \mathrm{C}$ in vitro but they failed to show expression of a number of genes known to be expressed exclusively in in vitro generated yeast cells, suggesting that the defect is unlikely to be the result of a failure to detect the local environment. A similar, albeit less severe, phenotype was observed when THP-1 human macrophages were used. An alternative explanation for the morphogenesis defect is that the phagocytosed conidia germinate aberrantly, however kinetic studies of germination for the $m s g A$ deletion strain failed to identify any differences compared to the wildtype under any condition. Coupled with the observation that overexpression of $m s g A$ at $37^{\circ} \mathrm{C}$ in vitro drives the formation of shorter ellipsoid yeast cells that resemble yeast during intracellular macrophage growth suggests that $m s g A$ is a key determinant of cell shape and is sufficient to redirect cellular morphogenetic programs towards infection-specific yeast cell formation.

Unlike other dimorphic pathogens where the yeast phase is marked by budding division, T. marneffei yeast cells divide by fission, so yeast and hyphal cells share similar polarised growth characteristics, up to the point of cell division. At cell division hyphal cells lay down a cell wall to generate a new cell compartment with no associated cell separation, whilst yeast cells undergo cell separation. The formation of elongated, filament-like yeast cells that are sometimes multiseptate by the $\Delta m s g A$ mutant strain during infection points to a disruption in the coordination of these processes and suggests that MsgA plays a vital role in processes that involve cell division (septation) and cell separation. While its precise role remains to be determined, the redistribution of MsgA from the entire cell membrane to that adjacent to the newly formed septum and before cell separation suggests that it is involved more at the cell separation stage than septation. The smaller, ellipsoid yeast cells produced by overexpressing $m s g A$ at $37^{\circ} \mathrm{C}$ in vitro and the defect in conidiogenesis for the $\triangle m s g A$ mutant strain are both consistent with this hypothesis that $m s g A$ is important for cell division and separation. Additionally, overexpressing $m s g A$ at $25^{\circ} \mathrm{C}$ in vitro results in increased septation along the hyphae producing shorter cellular compartments. Unlike yeast cell growth these compartments do not separate into individual cells, which is probably due to the absence of expression and/or activity of the yeast-specific machinery necessary for separation.

It is clear that $m s g A$ plays a fundamental role in the morphogenesis of yeast cells growing inside host cells and for conidial production during asexual development, The pakB gene of T. marneffei, encoding a p21-activated kinase, also plays an important role in cell division of yeast cells in macrophages and affect asexual development. In vitro overexpression of pakB alleles with either a mutated CRIB ( $\underline{C} d c 42 / \underline{R} a c$ Interactive Binding) or GBB (G $\underline{B}$ binding) domain, results in the production of yeast cells that resembled those produced during growth inside macrophages ${ }^{20}$. Additionally MsgA and PakB have complementary localisation patterns at septation sites during intracellular yeast formation. Together these are suggestive of coordinated effects on morphogenetic mechanisms that involve the regulation of cell division. Similar localization and morphological function has been observed in 
A

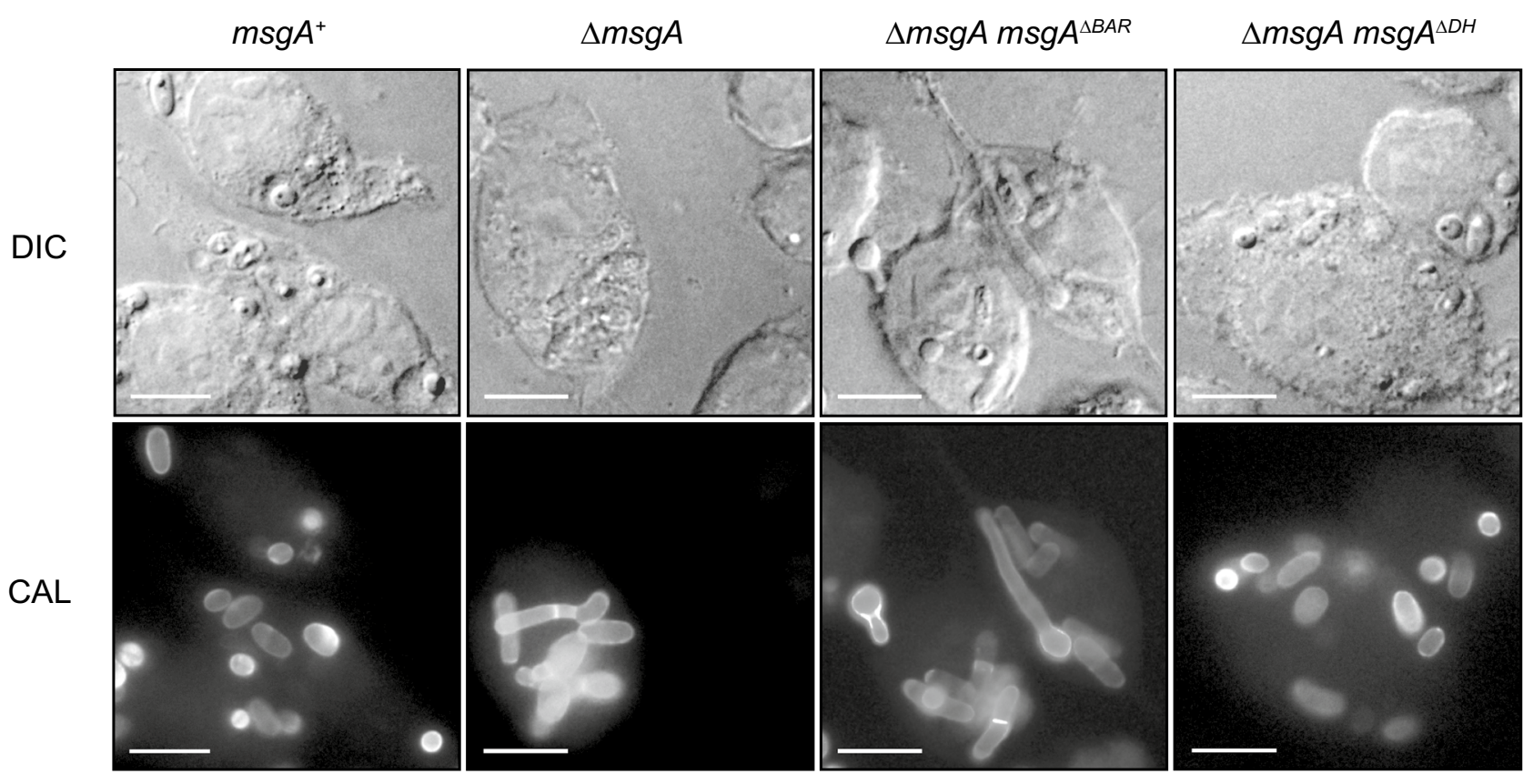

B

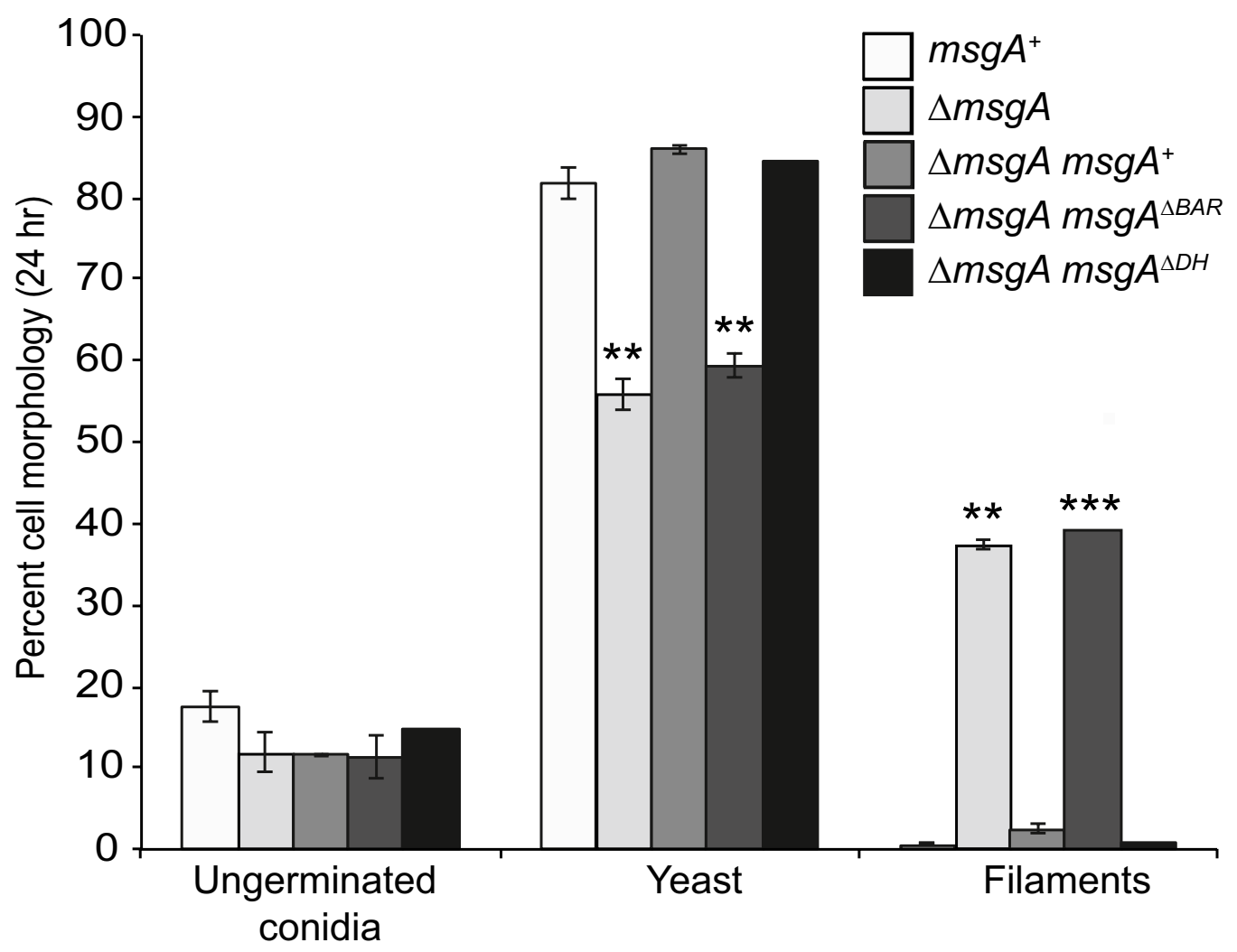


4Figure 6. The BAR domain of $m s g A$ contributes to morphology during growth inside macrophages. (A) LPS activated murine macrophages infected with conidia of either the wildtype ( $\left.m s g A^{+}\right), \Delta m s g A, \triangle m s g A$ $m s g A^{\Delta \mathrm{BAR}}$ or $\triangle m s g A m s g A^{\Delta \mathrm{DH}}$ strain. After $24 \mathrm{~h}$ cells were fixed, stained with calcofluor (CAL) and examined microscopically. Numerous small ellipsoid yeast cells dividing by fission were observed in macrophages infected with the wildtype and $\triangle m s g A m s g A^{\Delta \mathrm{DH}}$ strains. In contrast macrophages infected with $\triangle m s g A$ and $\triangle m s g A$ $m s g A^{\triangle \mathrm{BAR}}$ strains contained septate filaments and elongated yeast-like cells. (B) The effects of the $m s g A$ alleles on morphogenesis in macrophages were quantified at the $24 \mathrm{~h}$ post infection time point. The $\triangle m s g A m s g A^{\triangle \mathrm{BAR}}$ mutant strain shows $39.1 \pm 0.6 \%$ more filaments and $22.7 \% \pm 0.5$ fewer yeast cells compared to wildtype. These numbers are equivalent to those for the $\Delta m s g A$ strain. In contrast the $\triangle m s g A m s g A^{\Delta \mathrm{DH}}$ strain was comparable to the wildtype and complemented $\triangle m s g A$ strain. Error bars represented SEM with t-test values falling in the following range ${ }^{* *} \leq 0.05$ and ${ }^{* * *} \leq 0.001$. Images were captured using differential interference contrast (DIC) or with epifluorescence to observe calcofluor stained fungal cell walls (CAL). Scale bars are $10 \mu \mathrm{m}$.

S. cerevisiae for the GEF-like protein Lte1, which plays a vital role in activating the Mitotic Exit Network (MEN) and the formation of daughter bud cells. Lte1 is localized to the incipient bud cortex and lte1 mutants show delayed cytokinesis and aberrant daughter cell morphology ${ }^{35,36}$. Lte1 is activated by the PakB homologue Cla4, which enables its localisation to the bud where it inhibits machinery that prevents mitotic exit and thus proper bud formation ${ }^{37-40}$. In this respect LTE1 does not function as a GEF but rather in a separate signalling pathway controlling morphogenesis. T. marneffei and other filamentous fungi lack a clear, conserved orthologues of Lte1 and components involved in MEN, suggesting that they use an alternate pathway to accomplish this role and this may include the MsgA and PakB.

Unique domain structure of MsgA influences its function and localisation. The predicted gene product of $m s g A$ possesses a DH domain stereotypical of GEFs and involved in regulating GTP dependent interactions. However it lacks the auxiliary PH domain that is common to canonical GEFs and important for localisation. Instead MsgA has a BAR domain that is not present in any of the other Ras, Rho, Rsr, Arf, Rab and Ran GEFs in T. marneffei, but which is conserved in orthologues of MsgA in other ascomycete fungi. The function of the BAR domain has been characterised in a number of systems and it is clear that it is involved in membrane dynamics, particularly by its ability to oligomerise and induce membrane bending, but can also bind small GTPases and affect their function ${ }^{21}$. The data shows that an $m s g A$ allele missing the BAR domain $\left(m s g A^{\triangle \mathrm{BAR}}\right)$ failed to complement the aberrant yeast morphology phenotype observed in the $\triangle m s g A$ strain whereas a $m s g A$ allele missing the $\mathrm{DH}$ domain $\left(m s g A^{\Delta \mathrm{DH}}\right)$ fully rescued this phenotype. At least part of basis for this lack of complementation is likely to be due to the resultant loss of localisation of MsgA when the BAR domain is removed. This hypothesis is consistent with the correct localisation, and complementation, of the MsgA mutant protein that contains the BAR domain but lacks the $\mathrm{DH}$ domain. Like a number of other BAR domain proteins this suggests that part of its role may reside in its interaction with, and recruitment of, other factors to specific sites on the cell membrane $e^{41,42}$.

Proteins containing BAR domains are known to interact with many small GTPases including $\operatorname{Rac}^{42-44}$. In $T$. marneffei the Rac- (cflB), Cdc42- (cflA) and Ras- encoding (rasA) genes have been shown to play important and distinct roles in hyphal and yeast morphogenesis in vitro, yeast morphogenesis ex vivo, conidial germination and asexual development ${ }^{17,18,45}$, yet none of the phenotypes associated with the various mutant alleles examined in these studies, which include deletion, dominant activating and negative alleles, mimic those for $m s g A$ alleles. The $\operatorname{ras} A, c f l A$ and $m s g A$ genes play a role in yeast cell morphogenesis but the $m s g A$ gene effects are restricted to ex vivo yeast while the ras $A$ and $c f l A$ effects occur in all yeast cells. Moreover, the phenotypes of the $m s g A$ and rasA/cflA mutants with respect to yeast morphology are strikingly different. Similarly, the $c f l B$ and $m s g A$ genes play a role in asexual development but the effects of perturbing their function are different. Coupled with the observation that deletion of the DH domain does not appear to affect MsgA function and that msgA mutant yeast cells do not express in vitro yeast cell-specific genes, it seems that $m s g A$ controls yeast cell morphogenesis independently of these small GTPases and does not function in host recognition and signalling.

Canonical Rho GEFs have been investigated in a number of pathogenic fungi, and shown to play roles in cellular morphogenesis and pathogenicity ${ }^{11,12,46,47}$. Similarly, non-GEF-like BAR domain proteins have been associated with morphogenesis and virulence in a number of plant and human pathogenic fungi. For example, C. albicans rvs mutants affect hyphal morphogenesis, invasive growth and antifungal resistance through their involvement in endocytic mechanisms ${ }^{48}$. Also the rice blast fungus $M$. oryzae BAR domain proteins Rvs161 and Rvs167 are important for plant invasion through appresorial formation ${ }^{49}$. However non-canonical GEF-like proteins with a BAR domain are poorly understood in most systems, including fungi. In $S$. cerevisiae, the cell fusion regulator Fus2 has both a Dbl-homology domain and a diverged BAR domain. Fus2 forms a heterodimer with another BAR domain protein Rvs161, to recruit the signalling GTPase Cdc42 to the schmoo tip, promoting cell wall degradation and cell fusion during mating ${ }^{50,51}$. It is interesting to note that unlike canonical GEFs, Fus2 interacts with GTP-bound Cdc42 and shows no detectable GEF activity, suggesting that it is not acting as a GEF but rather a mating-specific effector via other protein domains. While the S. cerevisiae Fus2/Rvs161/Cdc42 complex regulates mating dynamics through protein localisation, and may share molecular mechanistic aspects with MsgA, it is not involved in maintaining cell morphology like MsgA. The best example of a DH domain protein with an associated BAR domain affecting cellular morphology is the human dynamin-binding scaffold protein Tuba, which localizes to brain synapses as puncta at the base of membrane ruffles and is involved in synaptic vessel endocytosis ${ }^{52-54}$. Membrane ruffling plays a crucial role in internalization during substrate acquisition and receptor availability control as well as cell motility ${ }^{55}$. Deletion of the BAR domain in Tuba abolishes dorsal ruffling of synaptic membranes and causes the mislocalisation of this protein throughout the cytoplasm, 

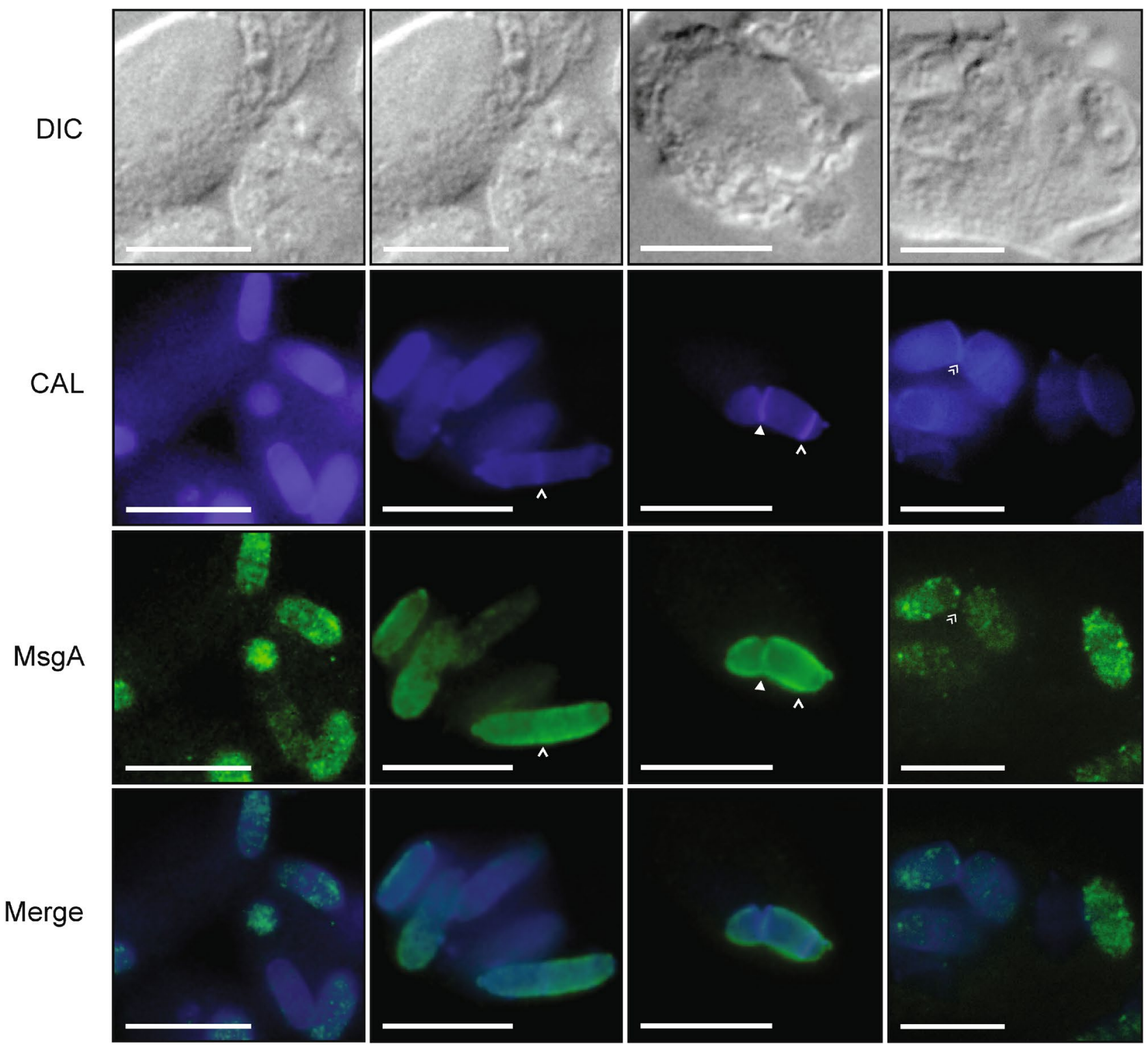

Figure 7. The BAR domain is necessary for the localisation of MsgA during growth inside macrophages. LPS activated murine macrophages infected with conidia from the wildtype ( $m s g A:: m C h e r r y), m s g A^{\triangle \mathrm{BAR}}:: m C h e r r y$ or $m s g A^{\Delta \mathrm{DH}}:: m C h e r r y$ strain. After $24 \mathrm{~h}$ cells were fixed and the MsgA-mCherry fusions (MsgA) were detected using an anti-mCherry rat monoclonal (3F10) primary and an anti-rat ALEXA488 goat secondary antibody. Yeast cells were also stained with calcofluor (CAL) to highlight the fungal cell wall. Both MsgA and CAL panels were overlayed to indicate overlapping localisation (Merge). The wildtype msgA::mCherry gene product showed clear punctate localisation at the cell periphery with puncta also within the cytoplasm (msgA::mCherry panel). This pattern of localisation was also evident for the $m s g A^{\Delta D H}:: m$ Cherry gene product ( $m s g A^{\Delta D H}:: m C h e r r y$ panel). However the $m s g A^{\triangle B A R}:: m$ Cherry gene product has lost its punctate pattern of localisation and appears uniformly within the cytoplasm. Additionally the $m s g A^{\triangle B A R}:: m C h e r r y$ gene product was mislocalized to the cell wall co-staining with calcofluor throughout the cell periphery ( $m s g A^{\triangle B A R}:: m$ Cherry panel). As with the wildtype $m s g A:: m$ Cherry strain (Fig. 5) the $m s g A^{\Delta D H}:: m$ Cherry gene product localized to the region immediately the adjacent division septum during cell separation (double arrowheads). In contrast the $m s g A^{\triangle B A R}:: m$ Cherry gene product was mislocalized to the cell wall, co-staining with calcofluor, during cell separation (solid arrowhead) but not at nascent septation sites prior to (single arrowheads) cell wall deposition. Images were captured using differential interference contrast (DIC) or with epifluorescence to observe calcofluor (CAL) and ALEXA488 fluorophores. Scale bars are $10 \mu \mathrm{m}$. 
suggesting that the BAR domain is necessary for facilitating correct localisation of Tuba during synaptic cell cytoskeletal dynamics $^{54}$. The phenotypic similarities between MsgA and this distantly related mammalian protein are striking and support the idea that BAR domains are important factors in determining cellular morphology across kingdoms.

Analysis of the msgA gene of T. marneffei shows that it is important for yeast cell morphogenesis during macrophage infection and in conidial production during asexual development. Although yeast cells divide by fission and conidia are formed by budding, both of these cell types require cell separation, which is unlike hyphal cells. Yeast cells formed in vitro also require cell separation but $m s g A$ does not appear to be required for this process. The distinction here may lie in the fact that yeast cell morphogenesis in vitro is always preceded by hyphal growth and the process of arthroconidiation that produces yeast cells in vitro may be mechanistically distinct. The data presented here suggests that $m s g A$ and the $\mathrm{p} 21$-activated kinase encoding pakB may function in the same pathway to control morphogenesis during infection. Further studies to identify binding partners of MsgA will shed light on the mechanism that controls cellular morphogenesis of T. marneffei during infectious growth.

Received: 23 January 2019; Accepted: 9 December 2020

Published online: 27 January 2021

\section{References}

1. Nemecek, J. C., Wüthrich, M. \& Klein, B. S. Global control of dimorphism and virulence in fungi. Science 312, 583-588 (2006).

2. Nguyen, V. Q. \& Sil, A. Temperature-induced switch to the pathogenic yeast form of Histoplasma capsulatum requires Ryp1, a conserved transcriptional regulator. Proc. Natl. Acad. Sci. U.S.A. 105, 4880-4885 (2008).

3. Webster, R. H. \& Sil, A. Conserved factors Ryp2 and Ryp3 control cell morphology and infectious spore formation in the fungal pathogen Histoplasma capsulatum. Proc. Natl. Acad. Sci. U.S.A. 105, 14573-14578 (2008).

4. Beyhan, S., Gutierrez, M., Voorhies, M. \& Sil, A. A temperature-responsive network links cell shape and virulence traits in a primary fungal pathogen. PLOS Biol. 11, e1001614 (2013).

5. Brandhorst, T. T., Wüthrich, M., Warner, T. \& Klein, B. Targeted gene disruption reveals an adhesin indispensable for pathogenicity of Blastomyces dermatitidis. J. Exp. Med. 189, 1207-1216 (1999).

6. Rooney, P. J., Sullivan, T. D. \& Klein, B. S. Selective expression of the virulence factor BAD1 upon morphogenesis to the pathogenic yeast form of Blastomyces dermatitidis: Evidence for transcriptional regulation by a conserved mechanism. Mol. Microbiol. 39, 875-889 (2001).

7. Andrianopoulos, A. Control of morphogenesis in the human fungal pathogen Penicillium marneffei. Int. J. Med. Microbiol. 292, 331-347 (2002).

8. Boyce, K. J. \& Andrianopoulos, A. Fungal dimorphism: The switch from hyphae to yeast is a specialized morphogenetic adaptation allowing colonization of a host. FEMS Microbiol. Rev. 39(6), 797-811 (2015).

9. Vanittanakom, N., Cooper, C. R., Fisher, M. C. \& Sirisanthana, T. Penicillium marneffei infection and recent advances in the epidemiology and molecular biology aspects. Clin. Microbiol. Rev. 19, 95-110 (2006).

10. Chant, J. \& Stowers, L. GTPase cascades choreographing cellular behavior: Movement, morphogenesis, and more. Cell 81, 1-4 (1995).

11. Fuchs, B. B., Tang, R. J. \& Mylonakis, E. The temperature-sensitive role of Cryptococcus neoformans ROM2 in cell morphogenesis. PLOS ONE 2, e368 (2007).

12. Tang, R. J. et al. Cryptococcus neoformans gene involved in mammalian pathogenesis identified by a Caenorhabditis elegans progenybased approach. Infect. Immun. 73, 8219-8225 (2005).

13. Herrmann, A., Tillmann, B. A. M., Schürmann, J., Bölker, M. \& Tudzynski, P. Small-GTPase-associated signaling by the guanine nucleotide exchange factors CpDock180 and CpCdc24, the GTPase effector CpSte20, and the scaffold protein CpBem1 in Claviceps purpurea. Eukaryot. Cell 13, 470-482 (2014).

14. Zhang, C. et al. FgBud3, a Rho4-interacting guanine nucleotide exchange factor, is involved in polarity growth, cell division and pathogenicity of Fusarium graminearum. Front. Microbiol. 9, 131 (2018).

15. Rossman, K. L., Der, C. J. \& Sondek, J. GEF means go: Turning on RHO GTPases with guanine nucleotide-exchange factors. Nat. Rev. Mol. Cell Biol. 6, 167-180 (2005).

16. Boyce, K. J. \& Andrianopoulos, A. Ste20-related kinases: Effectors of signaling and morphogenesis in fungi. Trends Microbiol. 19, 400-410 (2011).

17. Boyce, K. J., Hynes, M. J. \& Andrianopoulos, A. The CDC42 homolog of the dimorphic fungus Penicillium marneffei is required for correct cell polarization during growth but not development. J. Bacteriol. 183, 3447-3457 (2001).

18. Boyce, K. J., Hynes, M. J. \& Andrianopoulos, A. Control of morphogenesis and actin localization by the Penicillium marneffei RAC homolog. J. Cell Sci. 116, 1249-1260 (2003).

19. Boyce, K. J. \& Andrianopoulos, A. A p21-activated kinase is required for conidial germination in Penicillium marneffei. PLOS Pathog. 3, e162 (2007).

20. Boyce, K. J., Schreider, L. \& Andrianopoulos, A. In vivo yeast cell morphogenesis is regulated by a p21-activated kinase in the human pathogen Penicillium marneffei. PLOS Pathog. 5, e1000678 (2009).

21. Habermann, B. The BAR-domain family of proteins: A case of bending and binding?. EMBO Rep. 5, 250-255 (2004).

22. Zimmerberg, J. \& McLaughlin, S. Membrane curvature: How BAR domains bend bilayers. Curr. Biol. 14, R250-R252 (2004).

23. Dawson, J. C., Legg, J. A. \& Machesky, L. M. Bar domain proteins: A role in tubulation, scission and actin assembly in clathrinmediated endocytosis. Trends Cell. Biol. 16, 493-498 (2006).

24. Peter, B. J. et al. BAR domains as sensors of membrane curvature: The amphiphysin BAR structure. Science 303, 495-499 (2004).

25. Borneman, A. R., Hynes, M. J. \& Andrianopoulos, A. The abaA homologue of Penicillium marneffei participates in two developmental programmes: Conidiation and dimorphic growth. Mol. Microbiol. 38, 1034-1047 (2000).

26. Sambrook, J., Fritsch, E. F. \& Maniatis, T. Molecular Cloning: A Laboratory Manual (Cold Spring Laboratory Press, New York, 1989).

27. Boyce, K. J., Bugeja, H. E., Weerasinghe, H., Payne, M. J. \& Schreider, L. Strategies for the molecular genetic manipulation and visualization of the human fungal pathogen Penicillium marneffei. Fungal Genet. Rep. 59, 1-12 (2012).

28. Bugeja, H. E. et al. Tools for high efficiency genetic manipulation of the human pathogen Penicillium marneffei. Fungal Genet. Biol. 49, 772-778 (2012).

29. Fischer, R. \& Timberlake, W. E. Aspergillus nidulans apsA (anucleate primary sterigmata) encodes a coiled-coil protein required for nuclear positioning and completion of asexual development. J. Cell Biol. 128, 485-498 (1995).

30. Takei, K., Slepnev, V. I., Haucke, V. \& Pietro, D. C. Functional partnership between amphiphysin and dynamin in clathrin-mediated endocytosis. Nat. Cell Biol. 1, 33-39 (1999). 
31. Verstrepen, K. J., Jansen, A., Lewitter, F. \& Fink, G. R. Intragenic tandem repeats generate functional variability. Nat. Genet. 37, 986-990 (2005).

32. Verstrepen, K. J., Reynolds, T. B. \& Fink, G. R. Origins of variation in the fungal cell surface. Nat. Rev. Microbiol. 2, 533-540 (2004).

33. Yang, E. et al. Unraveling the molecular basis of temperature-dependent genetic regulation in Penicillium marneffei. Eukaryot. Cell 12, 1214-1224 (2013).

34. Boyce, K. J., Schreider, L., Kirszenblat, L. \& Andrianopoulos, A. The two-component histidine kinases DrkA and SlnA are required for in vivo growth in the human pathogen Penicillium marneffei. Mol. Microbiol. 82, 1164-1184 (2011).

35. Bertazzi, D. T., Kurtulmus, B. \& Pereira, G. The cortical protein Lte1 promotes mitotic exit by inhibiting the spindle position checkpoint kinase Kin4. J. Cell Biol. 193, 1033-1048 (2011).

36. Geymonat, M., Spanos, A., de Bettignies, G. \& Sedgwick, S. G. Lte1 contributes to Bfa1 localization rather than stimulating nucleotide exchange by Tem1. J. Cell Biol. 187, 497-511 (2009).

37. Höfken, T. \& Schiebel, E. A role for cell polarity proteins in mitotic exit. EMBO J. 21, 4851-4862 (2002).

38. Jensen, S., Geymonat, M., Johnson, A. L., Segal, M. \& Johnston, L. H. Spatial regulation of the guanine nucleotide exchange factor Lte1 in Saccharomyces cerevisiae. J. Cell Sci. 115, 4977-4991 (2002).

39. Seshan, A., Bardin, A. J. \& Amon, A. Control of Ltel localization by cell polarity determinants and Cdc14. Curr. Biol. 12, 2098-2110 (2002).

40. Yoshida, S., Ichihashi, R. \& Toh-e, A. Ras recruits mitotic exit regulator Lte1 to the bud cortex in budding yeast. J. Cell Biol. 161, 889-897 (2003).

41. Miki, H., Yamaguchi, H., Suetsugu, S. \& Takenawa, T. IRSp53 is an essential intermediate between Rac and WAVE in the regulation of membrane ruffling. Nature 408, 732-735 (2000).

42. Schorey, C. D., Boshans, R. L., McDonough, M., Stahl, P. D. \& Van Aelst, L. A role for POR1, a Rac1-interacting protein, in ARF6mediated cytoskeletal rearrangements. EMBO J. 16, 5445-5454 (1997).

43. Tarricone, C. et al. The structural basis of Arfaptin-mediated cross-talk between Rac and Arf signalling pathways. Nature 411, 215-219 (2001).

44. Van Aelst, L., Joneson, T. \& Bar-Sagi, D. Identification of a novel Rac1-interacting protein involved in membrane ruffling. EMBO J. 15, 3778-3786 (1996).

45. Boyce, K. J., Hynes, M. J. \& Andrianopoulos, A. The Ras and Rho GTPases genetically interact to co-ordinately regulate cell polarity during development in Penicillium marneffei. Mol. Microbiol. 55, 1487-1501 (2005).

46. Wendland, J. \& Philippsen, P. Cell polarity and hyphal morphogenesis are controlled by multiple Rho-protein modules in the filamentous ascomycete Ashbya gossypii. Genet. 157, 601-610 (2001).

47. Bassilana, M., Blyth, J. \& Arkowitz, R. A. Cdc24, the GDP-GTP exchange factor for Cdc42, is required for invasive hyphal growth of Candida albicans. Eukaryot. Cell 2, 9-18 (2003).

48. Douglas, L. M., Martin, S. W. \& Konopka, J. B. BAR domain proteins Rvs161 and Rvs167 contribute to Candida albicans endocytosis, morphogenesis, and virulence. Infect. Immun. 77, 4150-4160 (2009).

49. Dagdas, Y. F. et al. Septin-mediated plant cell invasion by the rice blast fungus Magnaporthe oryzae. Science 336, 1590-1595 (2012).

50. Ydenberg, C. A., Stein, R. A. \& Rose, M. D. Cdc42p and Fus2p act together late in yeast cell fusion. Mol. Biol. Cell 23, 1208-1218 (2012).

51. Smith, J. A., Hall, A. E. \& Rose, M. D. Membrane curvature directs the localization of Cdc42p to novel foci required for cell-cell fusion. J. Cell Biol. 216, 3971-3980 (2017).

52. Salazar, M. A. et al. Tuba, a novel protein containing bin/amphiphysin/Rvs and Dbl homology domains, links dynamin to regulation of the actin cytoskeleton. J. Biol. Chem. 278, 49031-49043 (2003).

53. Kovacs, E. M., Verma, S., Thomas, S. G. \& Yap, A. S. Tuba and N-WASP function cooperatively to position the central lumen during epithelial cyst morphogenesis. Cell Adh. Migr. 5, 344-350 (2011).

54. Kovacs, E. M., Makar, R. S. \& Gertler, F. B. Tuba stimulates intracellular N-WASP-dependent actin assembly. J. Cell Sci. 119, 2715-2726 (2006).

55. Hoon, J.-L., Wong, W.-K. \& Koh, C.-G. Functions and regulation of circular dorsal ruffles. Mol. Cell. Biol. 32, 4246-4257 (2012).

\section{Acknowledgements}

We would like to acknowledge the support and feedback of the various lab members who contributed to the ongoing discussion of this project. This work was supported by a National Health and Medical Research Council grant to AA. We also acknowledge the technical support by Jacob Calabria.

\section{Author contributions}

Listed using the CRediT taxonomy. Conceptualization: H.W., A.A. Formal analysis: H.W., H.E.B., A.A. Funding acquisition: A.A. Investigation: H.W. Methodology: H.W., H.E.B., A.A. Supervision: H.E.B., A.A. Writing-original draft: H.W., H.E.B., A.A. Writing-review and editing: H.W., H.E.B., A.A.

\section{Competing interests}

The authors declare no competing interests.

Additional information

Supplementary Information The online version contains supplementary material available at https://doi. org/10.1038/s41598-020-79593-4.

Correspondence and requests for materials should be addressed to A.A.

Reprints and permissions information is available at www.nature.com/reprints.

Publisher's note Springer Nature remains neutral with regard to jurisdictional claims in published maps and institutional affiliations. 
(c) (i) Open Access This article is licensed under a Creative Commons Attribution 4.0 International cc) License, which permits use, sharing, adaptation, distribution and reproduction in any medium or format, as long as you give appropriate credit to the original author(s) and the source, provide a link to the Creative Commons licence, and indicate if changes were made. The images or other third party material in this article are included in the article's Creative Commons licence, unless indicated otherwise in a credit line to the material. If material is not included in the article's Creative Commons licence and your intended use is not permitted by statutory regulation or exceeds the permitted use, you will need to obtain permission directly from the copyright holder. To view a copy of this licence, visit http://creativecommons.org/licenses/by/4.0/.

(C) The Author(s) 2021 